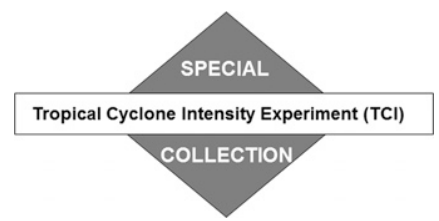

\title{
Satellite-Based Observations of Nonlinear Relationships between Vertical Wind Shear and Intensity Changes during the Life Cycle of Hurricane Joaquin (2015)
}

\author{
RUSSELL L. ELSBERRY \\ Naval Postgraduate School, Monterey, California, and University of Colorado, Colorado Springs, \\ Colorado Springs, Colorado \\ NATASHA BUHOLZER \\ Naval Postgraduate School, Monterey, California \\ CHRISTOPHER S. VELDEN \\ Cooperative Institute for Meteorological Satellite Studies, Madison, Wisconsin \\ MARY S. JORDAN \\ Naval Postgraduate School, Monterey, California
}

(Manuscript received 15 July 2019, in final form 13 February 2020)

\begin{abstract}
A CIMSS vertical wind shear (VWS-C) dataset based on reprocessed GOES-East atmospheric motion vectors (AMVs) at 15 -min intervals has a -0.36 correlation with the CIMSS Satellite Consensus (SATCON) intensity changes at 30-min intervals over the life cycle of Hurricane Joaquin (2015). Correlations are then calculated for four intensity change events including two rapid intensifications (RIs) and two decays, and four intensity change segments immediately before or after these events. During the first RI, the peak intensity increase of $16 \mathrm{kt}(6 \mathrm{~h})^{-1}\left(1 \mathrm{kt} \approx 0.51 \mathrm{~m} \mathrm{~s}^{-1}\right)$ follows a small VWS-C decrease to a moderate $8 \mathrm{~m} \mathrm{~s}^{-1}$ value (negative correlation). A $30-\mathrm{h}$ period of continued RI following the first peak RI occurred under moderate magnitude VWS-C (negative correlation), but with a rotation of the VWS-C direction to become more aligned with the southwestward heading of Joaquin. During the second RI, the peak intensity increase of $15 \mathrm{kt}(6 \mathrm{~h})^{-1}$ leads the rapid VWS-C increase (positive correlation), which the horizontal plots of VWS-C vectors demonstrate is related to an upper-tropospheric cyclone to the northeast of Joaquin. A conceptual model of ocean cooling within the anticyclonic track loop is proposed to explain a counterintuitive decreasing intensity when the VWS-C was also decreasing (positive correlation) during the Joaquin track reversal. These alternating negative and positive correlations during the four events and four segments of intensity change demonstrate the nonlinear relationships between the VWS-C and intensity changes during the life cycle of Joaquin that must be understood, analyzed, and modeled to improve tropical cyclone intensity forecasts, and especially RI events.
\end{abstract}

\section{Introduction}

The objective of this study is to demonstrate how two special satellite datasets from the Tropical Cyclone Intensity (TCI-15; Doyle et al. 2017) field experiment can be used to diagnose nonlinear relationships between environmental vertical wind shear (VWS) and intensity changes of Hurricane Joaquin (2015). Hendricks et al. (2018) have demonstrated a special Cooperative Institute Meteorological Satellite Studies (CIMSS) VWS dataset

\footnotetext{
Corresponding author: Russell L. Elsberry, relsberr@uccs.edu
}

reprocessed at 15 -min intervals provides a more precise documentation of the large $\left(\sim 15 \mathrm{~m} \mathrm{~s}^{-1}\right)$ VWS throughout most of the rapid decay period of Hurricane Joaquin, and also the timing of a rapid decrease in VWS following the rapid decay period. The primary focus of Hendricks et al. (2018) was a unique dataset of High Definition Sounding System (HDSS) dropwindsondes deployed from the NASA WB-57 that was utilized to calculate zero-wind

Publisher's Note: This article was revised on 1 May 2020 to correct a typographical error in the date given in the second to last paragraph of section 2 . 


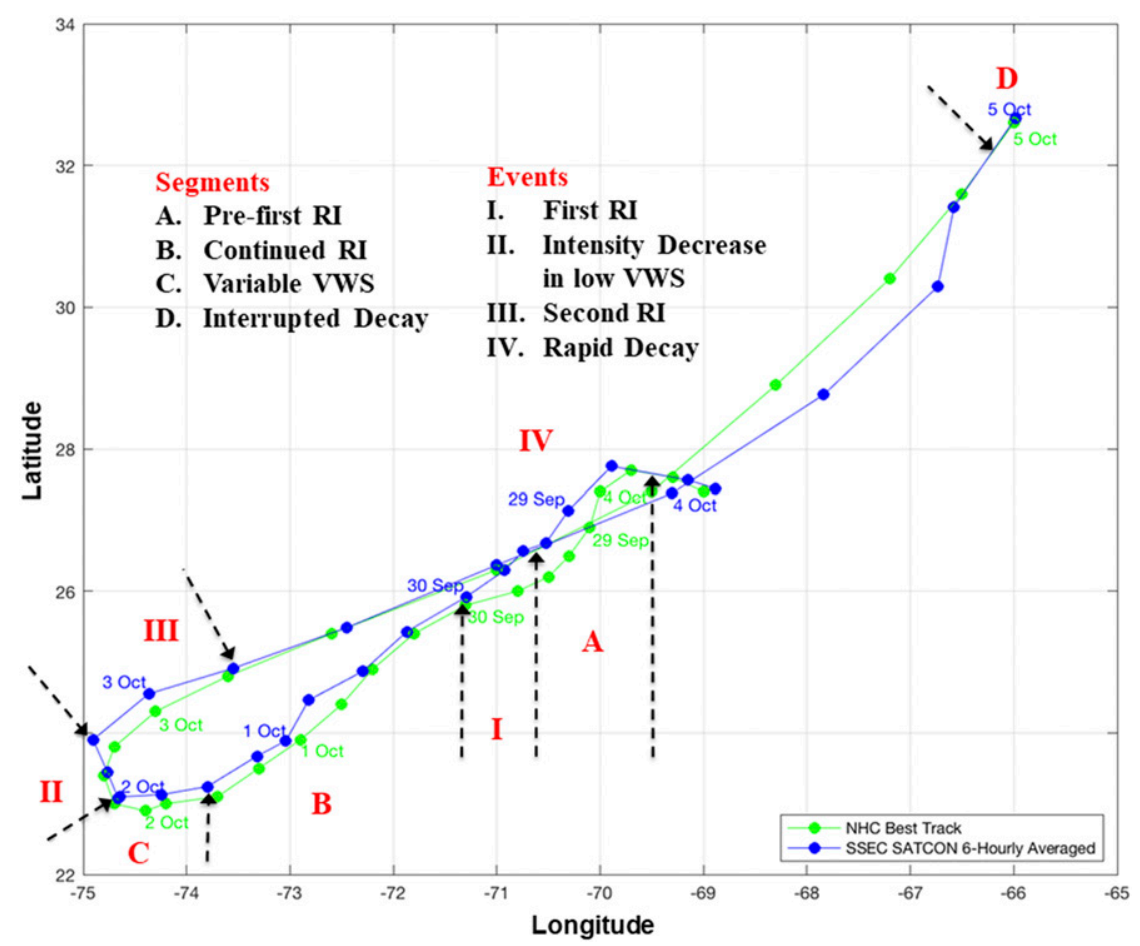

FIG. 1. Real-time SATCON positions derived primarily from the Advanced Dvorak Technique (ADT) averaged over $\pm 3 \mathrm{~h}$ (blue dots) and NHC best track positions (green dots) of Joaquin at 6-h intervals from 0600 UTC 28 Sep to 0000 UTC 5 Oct. Date/month positions are indicated at 0000 UTC for both the SATCON and the NHC working best track positions. Dashed arrows indicate the beginning SATCON times of segments A-D or Events I-IV defined in the insets.

centers during Joaquin center overpasses that reveal for the first time the vortex tilt structure through the entire troposphere as the HDSSs were deployed from $60000 \mathrm{ft}$. The HDSS datasets were also utilized to calculate the inertial stability profiles and the inner-core potential temperature anomalies in the vertical.

This study will examine the life cycle of Joaquin beginning when it became a tropical storm, moved southwestward to strike the Bahamas, and then made an anticyclonic loop with a track reversal to the northeast [Fig. 1, green dots are National Hurricane Center (NHC) best track]. As Joaquin moved over warmer waters toward the Bahamas, a period of rapid intensification [RI; here defined as equal to or greater than $30 \mathrm{kt}$ in $24 \mathrm{~h}\left(1 \mathrm{kt} \approx 0.51 \mathrm{~m} \mathrm{~s}^{-1}\right)$ ] began at 1200 UTC 29 September and lasted $\sim 60 \mathrm{~h}$. It was following the track reversal that the intensity decreased, but then a second RI occurred. Joaquin then underwent a rapid decay that was interrupted with a subsequent period of constant intensity (75 kt) according to the National Hurricane Center (NHC) best track (Berg 2016). However, Hendricks et al. (2018) had noted that real-time satellite intensity estimates suggested the rapid decay was not so abruptly interrupted as indicated by the NHC best track. As will be described later, the CIMSS satellite consensus (SATCON; Herndon and Velden 2018; Velden and Herndon 2020, manuscript submitted to Wea. Forecasting) indicated alternating intensification and decay periods occurred during the NHC constant intensity period. Furthermore, the 30-min interval SATCON estimates reveal short-term intensity changes during the two RI events that are the primary focus of this study.

Because this study is emphasizing satellite-based observations (note that only the Atlantic, and occasionally the eastern North Pacific, have reconnaissance aircraftbased low-level positions), this study will also examine the 30-min SATCON positions in Fig. 1 (blue dots). As these position estimates have considerable temporal variability, they have been averaged over $\pm 3 \mathrm{~h}$ for comparison with the NHC best track positions. During 29 September-3 October, these geostationary and polarorbiting satellite-based positions agree well with the NHC best tracks, albeit with a consistent bias to the west. However, there are two times (0600 and 1200 UTC 4 October) when Joaquin was rapidly moving northeastward that the SATCON positions are highly biased to the east. An Air Force reconnaissance mission 305 was presumably responsible for that NHC best track 
position at 1200 UTC 4 October (and similarly mission 303 for 0000 UTC 4 October and mission 304 for 0000 UTC 5 October), which is representative of the low-level vortex position and is likely to be very accurate. It is proposed that the eastward deviation of the SATCON position at 1200 UTC 4 October in Fig. 1 represents a vortex tilt since Joaquin was in a high VWS regime according to Hendricks et al. (2018) with values of $14.5 \mathrm{~m} \mathrm{~s}^{-1}$ at 1800 UTC 5 October, $9 \mathrm{~m} \mathrm{~s}^{-1}$ at 1900 UTC 4 October, and $14.5 \mathrm{~m} \mathrm{~s}^{-1}$ at 1800 UTC 5 October. Note that the SATCON position at 0600 UTC 4 October near $28.9^{\circ} \mathrm{N}, 67.8^{\circ} \mathrm{W}$, which is displaced eastward about $66 \mathrm{~km}$ from the NHC best track position near $29.0^{\circ} \mathrm{N}, 68.4^{\circ} \mathrm{W}$, likely also represents a vortex tilt. Creasey and Elsberry (2017) had utilized the HDSS dropwindsondes deployed from $60000 \mathrm{ft}$ during a center overpass by the NASA WB-57 to calculate the vortex tilt at 1900 UTC 4 October. Whereas the Joaquin vortex was vertical between 1.5 and $5.5 \mathrm{~km}$, the vortex tilt between 5.5 and $10.5 \mathrm{~km}$ was $32 \mathrm{~km}$ to the east, and then was poorly defined above $10.5 \mathrm{~km}$ (Elsberry et al. 2018, their Figs. 7a,b; Hendricks et al. 2018, their Fig. 8c). This vortex tilt estimate was just $6 \mathrm{~h}$ after the SATCON had a position near $30.3^{\circ} \mathrm{N}, 66.7^{\circ} \mathrm{W}$ that was approximately $55 \mathrm{~km}$ to the east of the NHC best track position near $30.4^{\circ}, 67.2^{\circ} \mathrm{W}$ (Fig. 1). Unfortunately, no high-altitude NOAA Gulfstream-IV datasets are available for validation of any of the SATCON positions after the 1200 UTC 2 October mission because the Gulfstream-IV had been diverted to the eastern North Pacific. Indeed, the only other Gulfstream-IV missions were at 0000 UTC and 1200 UTC 1 October and at 0000 UTC 2 October, and these were times that the NHC best track positions and SATCON positions were in good agreement. Because large vortex tilts are highly relevant to intensity change predictions, validations with the Gulfstream-IV are needed of SATCON position differences from the low-level center positions observed by recon aircraft.

While another forecast challenge with regard to Joaquin was the failure of the U.S.-based numerical models (and thus the NHC) to correctly forecast the northeastward track of Joaquin following the track reversal (not shown), the focus of this study is on the environmental VWS that may have contributed to the two RIs, the intensity changes during the track reversal, and then the interruption of the rapid decay that according to the NHC was followed by a constant intensity period. Jorgensen (2017) had demonstrated that among the Hendricks et al. (2010) environmental factors that best compared with the Joaquin 6-h best track intensity changes was the environmental VWS from either the Statistical Hurricane Intensity Prediction Scheme (SHIPS; DeMaria et al. 2005) or the CIMSS technique (Gallina and Velden 2002; Velden and Sears 2014). Whereas the SHIPS simply takes the difference between the Global Forecast System (GFS) 200- and 850-hPa horizontal wind analyses over a 500-km-radius circle, the CIMSS approach utilizes a local threedimensional analysis of high-density atmospheric motion vectors (AMVs; Velden et al. 2005) to calculate horizontal wind analyses at mandatory levels with much less dependence on the 6-h GFS forecast as a background than does the SHIPS technique. Then the CIMSS VWS (hereafter VWC-C) is the vector difference between the pressure-weighted mean wind fields in the 150-300- and the 700-950-hPa layers. Both approaches use a vortex filtering methodology in the final VWS estimate.

Following Jorgensen (2017) and Hendricks et al. (2018), the following correlations of intensity changes with only VWS as the leading environment factor will highlight nonlinearities during four intensity change segments A-D and four Events I-IV (to be described in section 3 ) that are indicated along the tracks in Fig. 1. Since other environmental factors (e.g., heat fluxes, moisture content, temperature/moisture advection, cloud-top divergence) are not available on the temporal and spatial scales of the VWS-C or the SATCON intensities, the correlations will be interpreted in relation to, or associated with, the VWS characteristics only.

To provide a baseline that will illustrate the advantages of 15-min VWS-C datasets and the need for 30-min SATCON intensities, Velden and Sears (2014, their Fig. 6) had correlated the initial 6-hourly SHIPS VWS and the CIMSS VWS with the subsequent intensity changes from +6 to $+72 \mathrm{~h}$ for 824 analyses of Atlantic TCs during 2008-10. Considering just the initial VWS analyses, the CIMSS and SHIPS had linear correlations with the +6 -h intensity change from -0.21 to -0.24 , respectively. In this Joaquin study, the linear correlation coefficient of the NHC best track intensity changes over 6-h intervals (and thus applicable at the midtime) with the SHIPS VWS (hereafter VWS-S) averaged over that 6-h interval during the life cycle of Joaquin is only 0.01 (Fig. 2). Part of this lack of correlation may be because the NHC best track intensities are only digitized in 5-kt increments, which leads to two periods of constant intensity changes of $-10 \mathrm{kt}(6 \mathrm{~h})^{-1}$ between 0300 and 2100 UTC 4 October, and $0 \mathrm{kt}(6 \mathrm{~h})^{-1}$ between 0300 UTC 5 October and 0300 UTC 6 October when the VWS-S was rapidly varying in magnitude. Some limitations of only having these VWS-S products at 6-h intervals are illustrated by the large VWS-S deviations at 0300 and 2100 UTC 4 October compared to the $6 \mathrm{~h}$ prior and subsequent values. In addition, note the smaller deviations at 1500 UTC 29 September and 

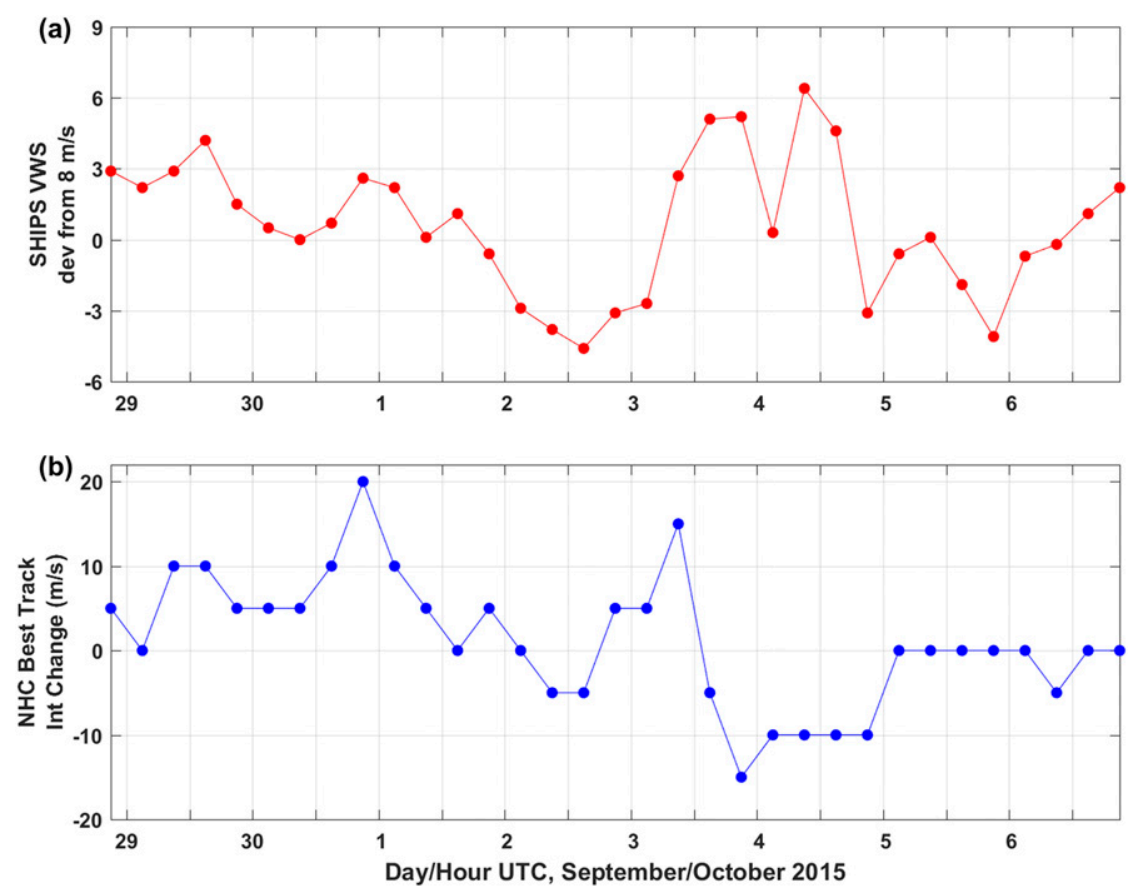

FIG. 2. (a) SHIPS vertical wind shear (VWS-S) deviations from $8 \mathrm{~m} \mathrm{~s}^{-1}$ (moderate wind shear) and (b) the NHC best track intensity changes per $6 \mathrm{~h}$ for Hurricane Joaquin from 2100 UTC 28 Sep to 2100 UTC 6 Oct 2015.

2100 UTC 5 October from the smoother time variations that might be expected for large-scale environmental VWS.

It is also noteworthy that during 2015 the VWS-S was being calculated from an analysis based on background 6-h GFS forecasts that only included operationally produced satellite-derived AMVs at the 6-h assimilation times. Furthermore, these AMVs incorporated in the data assimilation for the GFS had been thinned to be appropriate for the effective GFS horizontal grid resolution. Finally, strict operational quality control criteria designed primarily for large-scale analyses were being applied relative to the wind fields in the model-predicted TC vortex that had been relocated from the 6-h GFS forecast position to the observed position. Consequently, AMVs properly reflecting the actual Joaquin vortex wind structure and outflow may easily have been rejected in the quality control step because of their substantial deviations from the generally smoother GFS vortex structure and outflow.

By contrast, the special AMV dataset reprocessed by CIMSS at 15-min intervals was based on GOES-13 rapid-scan images for the lifetime of Joaquin. The AMV reprocessing strategy was to focus on the spatial and temporal scales of Joaquin by utilizing the higher temporal sampling afforded by the rapid scanning, adjust the targeting and tracking metrics to increase the spatial sampling of cloud motions, and relax the quality control to allow greater deviations from the background modelguess wind fields. Further details can be found in Velden et al. (2017), Velden and Stettner (2018), and Stettner et al. (2019). This effort was also part of a demonstration for what is now emerging operationally in terms of targeting TCs from the new generation of geostationary satellites such as the GOES-R series, the Himawari series, and the Meteosat Third Generation series.

As described above for the operational CIMSS VWS (and with more details in section 2), these 15-min AMV datasets were then analyzed onto high-resolution grids using a three-dimensional recursive filter to create CIMSS VWS (hereafter VWS-C) fields. Although a 6-h GFS forecast is utilized as a background, these VWS-C fields are primarily dependent on the reprocessed high spatial resolution AMVs. These 15-min interval VWS$\mathrm{C}$ datasets will be shown to better represent the high temporal variability in the environmental VWS fields during Joaquin. In addition, intensity estimates at 30-min intervals derived from the SATCON satellite consensus method (Herndon and Velden 2018; Velden and Herndon 2020, manuscript submitted to Wea. Forecasting) will be employed to better represent the high-frequency intensity changes, especially during Joaquin's RI periods. Both of these enhanced datasets are further described in section 2. In section 3, the four intensity change events during the life cycle of Joaquin 


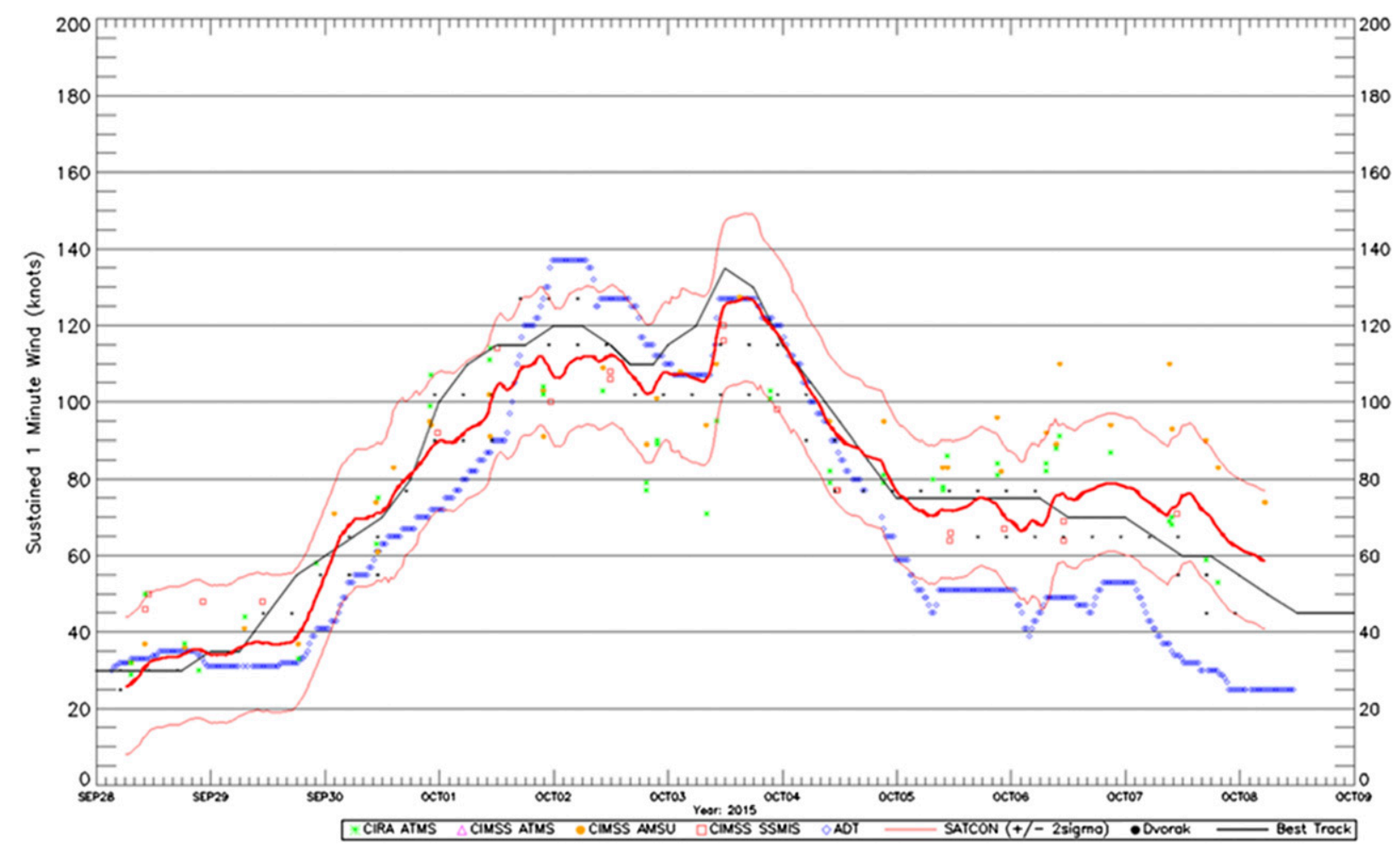

FIG. 3. Real-time CIMSS tropical cyclone SATCON intensity (kt) estimates at 30-min intervals (red line) from 0000 UTC 28 Sep to 0000 UTC 8 Oct 2015 for Hurricane Joaquin that incorporates CIRA ATMS (green stars), CIMSS ATMS (magenta triangle), CIMSS AMSU (orange circles), CIMSS SSMIS (red squares), and ADT (black diamonds). Also displayed are the Dvorak technique values (black dots) and NHC working best track intensities (black line) that are digitized at 5-kt increments typically at 6-h synoptic times.

and the four segments of intensity changes before or after these four events (see Fig. 1) will be described, and the environmental influence of VWS-C (and the ocean cooling) will be related to these events and segment intensity changes. A summary of the nonlinear relationships between the environmental influences and the intensity changes during Joaquin inferred from high temporal resolution satellite-based observations will be given in section 4 .

\section{Datasets and linear correlations of intensity change and VWS-C}

Hendricks et al. (2018) describe the special VWS-C dataset that was created based on the reprocessed 15-min AMVs. In creating the VWS-C fields, the TC vortex associated with the AMVs plus the background 6-h GFS analysis is removed to a radius of $600 \mathrm{~km}$ in the $150-300-\mathrm{mb}$ layer and to $800 \mathrm{~km}$ in the 700-950-mb layer wind analyses $(1 \mathrm{mb}=1 \mathrm{hPa})$. In this study, the TC-centric VWS-C values have been averaged over a circle of $350-\mathrm{km}$ radius relative to the center rather than the $500-\mathrm{km}$ radius used by Hendricks et al. (2018). This smaller averaging radius is a compromise between the $500-\mathrm{km}$ radius VWS-S and the center-point VWS value utilized in the operational CIMSS, and because it will be shown later that the upper-tropospheric vortex of Joaquin is confined between troughs to the west and to the east. It will also be demonstrated in section 3 that there are notable differences in timing of large intensity change events throughout Joaquin's life cycle using the 15-min VWS-C dataset. In addition to area-averages of the VWS-C magnitudes and directions, horizontal plots of the VWS-C vectors relative to the center of Joaquin will be displayed.

The other high temporal resolution dataset for analysis of the Joaquin evolution is the intensity estimates from SATCON (Fig. 3), which is a consensus of objective satellite intensity algorithms that are combined with a statistically derived weighting scheme that emphasizes the strengths and minimizes the weaknesses of the individual intensity algorithms (http://tropic.ssec.wisc.edu/ misc/satcon/info.html). The microwave sounder-based algorithms used in the consensus are the CIMSS Advanced Technology Microwave Sounder (ATMS), the Cooperative Institute for Research in the Atmosphere (CIRA) ATMS, the CIMSS Advanced Microwave Sounding Unit (AMSU), and the CIMSS Special Sensor Microwave Imager/Sounder 
(SSMIS). The Advanced Dvorak Technique (ADT; Olander and Velden 2019) algorithm utilizes infrared imagers on geostationary meteorological satellites and is thus highly dependent on the TC cloud structures and patterns.

The microwave sounder algorithms are most accurate when the eye size is large compared to the field of view resolution of the instrument. Thus, the AMSU, ATMS, and SSMIS intensities are weighted heavier during times when the eye is larger. Temporal availability is also something considered when compiling the SATCON intensities. An advantage of the ADT is the rapid refresh with intensity analyses nominally every $30 \mathrm{~min}$. Since the microwave observations over a target TC from polar orbiters are less frequent, true SATCON intensity estimates are only available for those times. However, those intensity estimates can be interpolated to the ADT timeframes and time weighted to provide a continuous SATCON record.

These real-time SATCON intensities (red line, Fig. 3) have noticeable deviations from the NHC working best track (WBT, black line) during the entire life cycle of Joaquin. These 30-min SATCON intensity values for Joaquin are an alternative to the WBT intensities because the SATCON intensities are digitized to $1 \mathrm{kt}$ (versus $5 \mathrm{kt}$ for the WBT) and include details of Joaquin's RIs that tend to be smoothed out in the 6-h WBT intensities. For example, the SATCON and the WBT intensities are essentially identical at $35 \mathrm{kt}$ at $0600 \mathrm{UTC}$ 29 September and $\sim 60 \mathrm{kt}$ at 0000 UTC 30 September. However, the WBT begins the first RI with a linear intensity increase from 0600 to 1800 UTC 29 September. Based primarily on the ADT time series (blue dots, Fig. 3) that is constant from 0000 to 1800 UTC 29 September, the SATCON (red line) does not begin the first RI until 1800 UTC. Consequently, the 6-h peak RI intensity change to $\sim 60 \mathrm{kt}$ at 0000 UTC 30 September for the SATCON is much larger than in the WBT file because of this delay in the starting time, which is here attributed to a convective burst detected by the high temporal resolution infrared imagery. A similar difference in the initial timing, and thus peak magnitude, occurs for the second RI. The WBT (black line) begins the second RI around 2100 UTC 2 October with a slower increase to the peak intensity of $135 \mathrm{kt}$ at 1200 UTC 3 October. By contrast, the SATCON representation of the second RI has a delayed start time of 0900 UTC 3 October with an extremely rapid increase in intensity to $\sim 128 \mathrm{kt}$ in about $2 \mathrm{~h}$ (red line), which is here attributed to a convective burst detected between two synoptic times due to the high temporal resolution infrared imagery on which the ADT is based.

The raw 6-h changes in the 30-min SATCON intensities and the 15-min VWS-C magnitude and direction evolutions are shown in Fig. 4. Because the 30-min SATCON intensities in Fig. 3 have short-term variability, the 6-h intensity changes have even larger variability such that the synoptic time scale trends are obscurred (Fig. 4a). For correlation analysis comparable to the VWS-S versus NHC intensity correlation in Fig. 2, the 30-min SATCON intensities in Fig. 3 are first averaged over a 6 -h period (i.e., $\pm 3 \mathrm{~h}$ ) to provide values at traditional synoptic times $(0000,0600,1200$, and 1800 UTC). The raw 15-min VWS-C directions are shown in Fig. 4b and the raw VWS-C magnitudes, which are expressed as deviations from a "moderate" value that is tentatively chosen to be $8 \mathrm{~m} \mathrm{~s}^{-1}$ to be consistent with Gallina and Velden (2002), are shown in Fig. 4c. For the correlation with the SATCON intensity changes, these VWS-C deviations will be averaged over the $6 \mathrm{~h}$ between these synoptic times, and thus apply at the midpoint of the 6-h SATCON intensity changes. For example, the 15-min VWS-C magnitudes in Fig. 4c from 0000 to 0600 UTC are averaged and assigned to 0300 UTC, and the correlation will be with the 6-h SATCON intensity change (0600 UTC minus 0000 UTC) that is also at the midpoint time. During the period between 0000 and 1200 UTC 30 September the VWS-C directions (Fig. 4b) rotate from west of north $\left(<360^{\circ}\right)$ to east of north $\left(0^{\circ}\right)$, so the 6-h averaging had to address this discontinuity as the VWS-C directions rotated through north.

The 6-h SATCON intensity changes after the averaging described above are displayed in Fig. 5a and the 6-h averages of the VWS-C directions and VWS-C magnitudes as deviations from $8 \mathrm{~m} \mathrm{~s}^{-1}$ are shown in Figs. $5 \mathrm{~b}$ and $5 \mathrm{c}$, respectively. The linear correlation coefficient between these 6-h SATCON intensity changes and the 6-h average VWS-C deviations from a moderate VWS of $8 \mathrm{~m} \mathrm{~s}^{-1}$ is -0.36 . By contrast, a correlation of -0.25 was obtained when this VWS-C dataset was correlated with the NHC intensity changes. These correlation coefficients indicate that it is the improvement of the 15-min VWS-C relative to the VWS-S that is the major contribution to the correlation of VWS-C to intensity change. However, the utilization of the smoothed, high-frequency SATCON intensities versus the 6-h NHC best track intensity changes also has a substantial contribution.

One of these contributions to the higher correlation of the VWS-C with the SATCON intensity changes is that the first RI in the SATCON dataset with a maximum of about $19 \mathrm{kt}$ in $6 \mathrm{~h}$ (Fig. 5a) is coincident in time with a decrease in VWS-C at 2100 UTC 29 September (Fig. 5c). By contrast, the first RI in the NHC best track file peaked at 2100 UTC 30 September when the VWS-S was about $11 \mathrm{~m} \mathrm{~s}^{-1}$ (Fig. 2), and the VWS-C deviation 
(a)

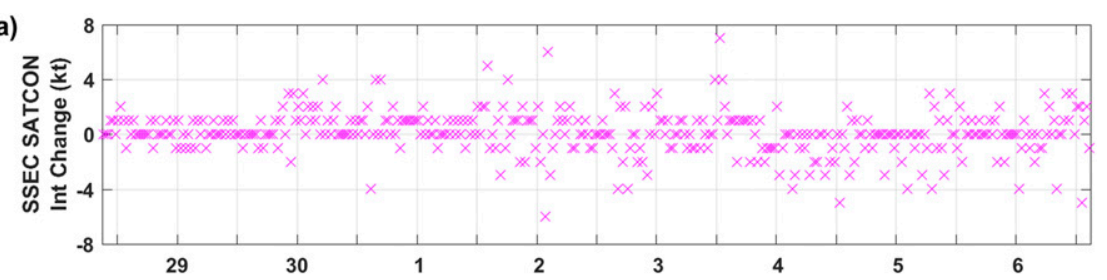

(b)
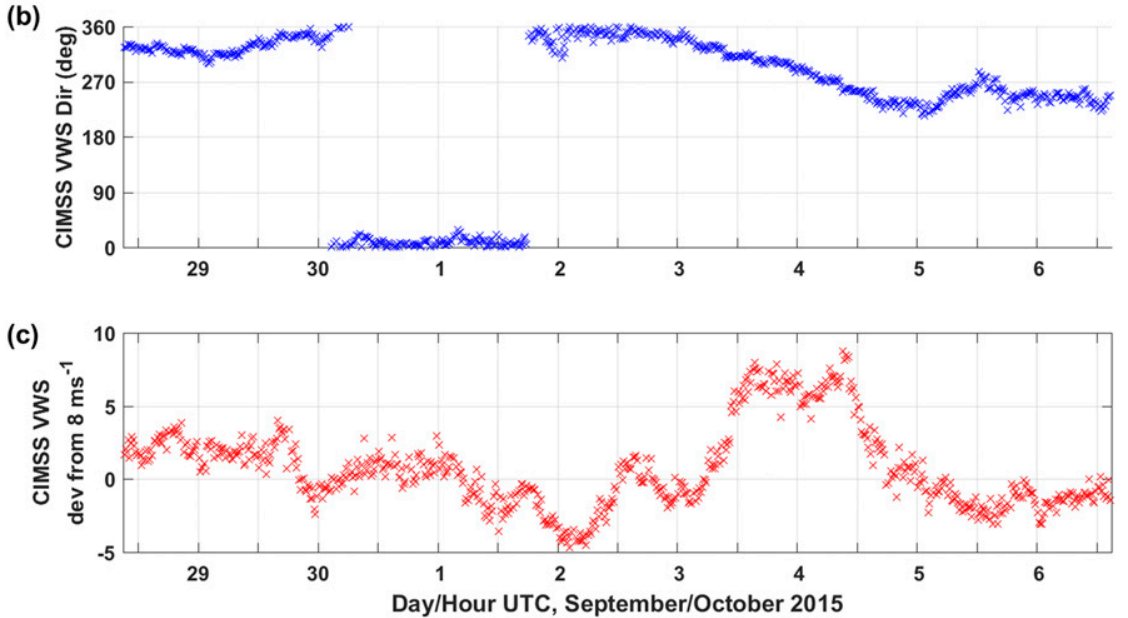

FIG. 4. Special datasets of (a) 30-min SATCON intensity (maximum surface wind; kt) changes over $6 \mathrm{~h}$, and 15-min (b) VWS-C direction, and (c) VWS-C magnitude deviations from moderate shear $\left(8 \mathrm{~m} \mathrm{~s}^{-1}\right)$ for Hurricane Joaquin from 0900 UTC 28 Sep to 1500 UTC 6 Oct 2015. The VWS-C directions and magnitudes are averaged over a circle of $350-\mathrm{km}$ radius from the center.

from $8 \mathrm{~m} \mathrm{~s}^{-1}$ was more in the moderate range with a value of $+1 \mathrm{~m} \mathrm{~s}^{-1}$.

Both the SATCON (Fig. 5a) and the NHC best track (Fig. 2) have the second RI event peaking at 0900 UTC 3 October at a time when both the VWS-C (Fig. 5c) and the VWS-S (Fig. 2) are becoming large (+5 and $+3 \mathrm{~ms}^{-1}$ relative to a moderate VWS of $8 \mathrm{~m} \mathrm{~s}^{-1}$, respectively). Consequently, the contribution to the correlation coefficient at this time would actually be positive rather than the negative correlations as above. It should be noted for later discussion that the VWS-C direction (Fig. 5b, blue dots) rotated through north following the first RI to become more aligned with Joaquin's direction of motion (red dots).

Another counterintuitive feature in Fig. 5 is that from 0900 UTC 1 October to 0300 UTC 2 October the VWS-C (Fig. 5c) is becoming smaller when the SATCON 6-h intensity change magnitudes (Fig. 5a) are also becoming smaller. Although the VWS-C then increases to moderate values $\left(\sim 8 \mathrm{~m} \mathrm{~s}^{-1}\right)$ at $0900 \mathrm{UTC}$ 2 October, the SATCON intensity change is actually a decay of $5 \mathrm{kt}(6 \mathrm{~h})^{-1}$ at 1500 UTC 2 October just before the start of the second RI event. These counterintuitive intensity changes are occurring during the Joaquin track reversal from a storm motion of $30^{\circ}$ (toward the south-southwest) at 0900 UTC 1 October to a storm motion of $240^{\circ}$ (toward the east-northeast) at $0300 \mathrm{UTC}$ 3 October (Fig. 5b).

In summary, simply calculating a linear correlation of 6-h SATCON intensity changes with the 6-h averaged VWS-C over the entire life cycle of Joaquin may be obscuring important shorter-term physical processes in the environmental interaction with Joaquin. Thus, the Joaquin intensity evolution will be separated into four events, and the VWS-C directions relative to the storm motion directions illustrated in Fig. 5b will be considered in relation to these intensity change events. The objective is to better understand how these short-term environmental VWS-C variations and internal TC responses in terms of the SATCON intensity changes may be related to the two RI events and to the Joaquin track reversal.

\section{Nonlinear relationships between the SATCON intensity changes and VWS-C}

Rather than calculating a linear correlation over the entire life cycle of Joaquin of SATCON intensity changes with the environmental VWS-C calculated as an average within a radius of $350 \mathrm{~km}$ of the center of 

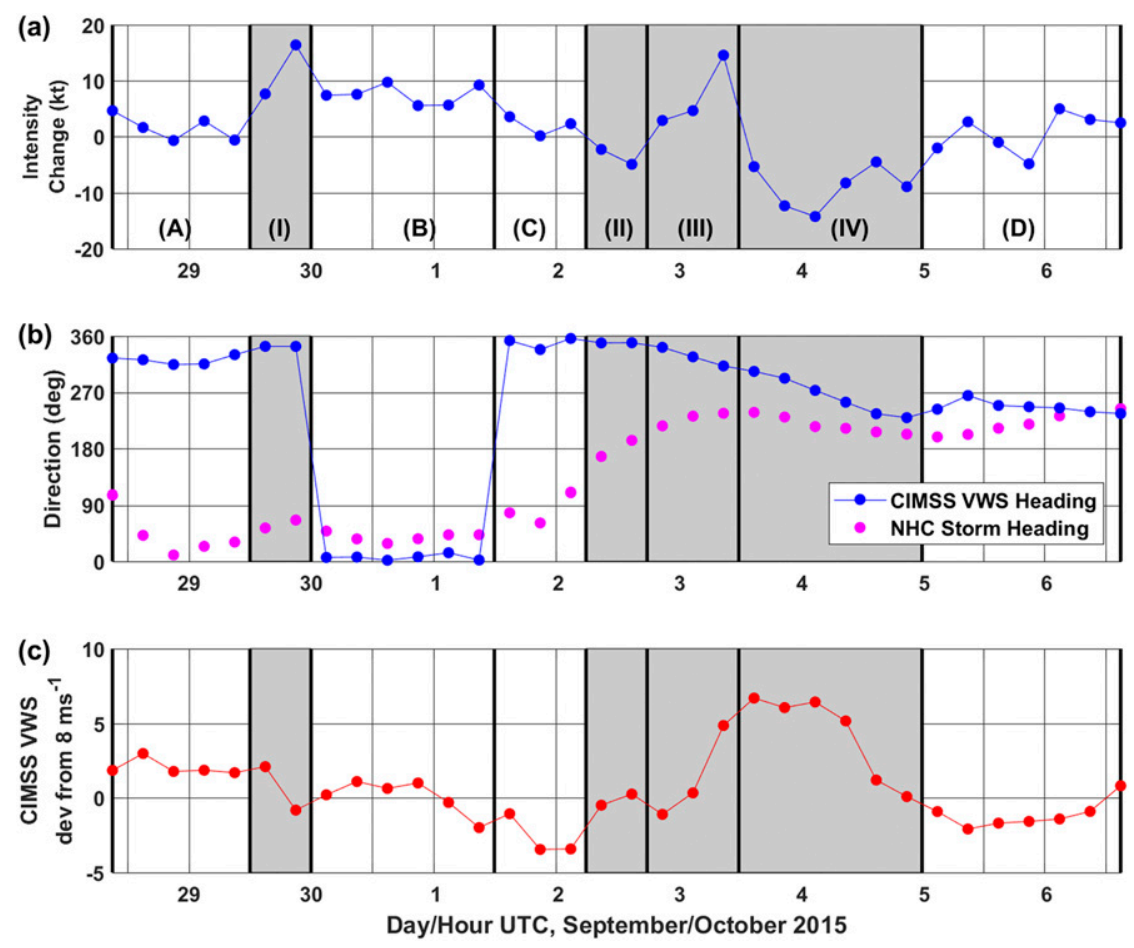

FIG. 5. As in Fig. 4, but for (a) 6-h differences of the 30-min SATCON intensities (kt) that have been first averaged over $\pm 3 \mathrm{~h}$ and (b) the 15-min VWS-C directions (blue dots) and (c) magnitudes as deviations from $8 \mathrm{~m} \mathrm{~s}^{-1}$ are averaged over $6 \mathrm{~h}$. The NHC storm directions each $6 \mathrm{~h}$ are pink dots in (b). Intensity change Events I-IV (shaded regions) and segments A-D (see text for definitions) are defined in (a).

Joaquin, four intensity change events (shaded areas in Fig. 5) and four intensity change segments have been defined. Averages and correlations of the SATCON intensity changes per $6 \mathrm{~h}$ and VWS-C (expressed as a deviation from a moderate value of $8 \mathrm{~m} \mathrm{~s}^{-1}$ ) within these segments and events are provided in Table 1 (columns 2-4). As these correlations are all for short periods (especially for Events I-III) in a single storm, the intent is not to imply or demonstrate statistical significance. Rather, the objective is to demonstrate nonlinear relationships by the changes in the signs of these correlations. That is, the correlations in these segments and events may have the expected negative sign (decreasing intensities in large or increasing VWS-C) or the counterintuitive positive sign (increasing intensities with increasing VWS-C as a deviation from a moderate VWS of $8 \mathrm{~m} \mathrm{~s}^{-1}$ ). Indeed, it will be demonstrated that both RI and rapid decay can occur in near-moderate VWS-C. Another objective of Table 1 is to highlight the intensity changes in association with the VWS-C direction changes (column 5) and the storm direction changes (column 6) during the track reversal of Joaquin. Note that the magnitudes of the differences between the VWS-C direction and the storm direction (column 8) are large when these headings are opposing (pretrack reversal) and are small when these directions are becoming aligned after the track reversal of Joaquin.

These events and segments were defined by first selecting four intensity change events of most interest. Two RI events (Events I and III), a period of intensity decrease in low VWS-C (Event II), and the rapid decay after the second RI (Event IV) were chosen as time periods that merited further investigation. Segments were then chosen as time periods to understand factors that contributed to the defined events or time periods to study the impacts of the defined events on the environmental VWS-C and intensity change. Recall that the intensity changes are per $6 \mathrm{~h}$, but the traditional definition of RI as $30 \mathrm{ktday}^{-1}$ will be applied in defining events (and for rapid decay). Following Gallina and Velden (2002), the moderate VWS-C has been tentatively defined as being centered on $8 \mathrm{~m} \mathrm{~s}^{-1}$. A recent statistical analysis by Wang et al. (2015) of the effects of VWS on TC intensity changes in the western North Pacific also found $\sim 8 \mathrm{~m} \mathrm{~s}^{-1}$ was a threshold value between intensification and decay. The Rios-Berrios and Torn (2017) moderate vertical wind shear definitions are not selected because they are based on the SHIPS VWS. 
TABLE 1. Definitions and characteristics of Joaquin intensity change segments A-D (top four rows) and Events I-IV (bottom four rows) with columns for average values of SATCON intensity change per $6 \mathrm{~h}$, vertical wind shear (VWS-C) magnitude ( $\mathrm{m} \mathrm{s}^{-1}$ ) as a deviation from moderate wind shear, correlation coefficient of VWS-C magnitude deviation from moderate VWS-C and SATCON intensity change, VWS-C direction (degrees from), storm direction, and the difference between the storm direction (S.D) and vertical wind shear direction. Dates/times in the first column are in UTC.

\begin{tabular}{|c|c|c|c|c|c|c|}
\hline & $\begin{array}{l}\text { Intensity change } \\
\text { per } 6 \mathrm{~h}(\mathrm{kt})\end{array}$ & $\begin{array}{c}\text { VWS magnitude } \\
\text { deviation from } 8 \mathrm{~m} \mathrm{~s}^{-1}\end{array}$ & $\begin{array}{l}\text { VWS-C/ } \\
\text { SATCON } \\
\text { correlation }\end{array}$ & $\begin{array}{c}\text { VWS-C } \\
\text { direction } \\
\left(^{\circ}\right)\end{array}$ & $\begin{array}{c}\text { Storm } \\
\text { direction } \\
\left({ }^{\circ}\right)\end{array}$ & $\begin{array}{l}\text { Magnitude of delta } \\
\text { S.D and VWS }\left(^{\circ}\right)\end{array}$ \\
\hline \multicolumn{7}{|l|}{ Segment } \\
\hline $\begin{array}{c}\text { A: } 0900 \text { UTC } 28 \text { Sep- } \\
0900 \text { UTC } 29 \text { Sep }\end{array}$ & 1.6 & 2.0 & 0.12 & 304 & 043 & 261 \\
\hline $\begin{array}{c}\text { B: } 0300 \text { UTC } 30 \text { Sep- } \\
0900 \text { UTC } 1 \text { Oct }\end{array}$ & 7.5 & 0.11 & -0.34 & 006 & 039 & 033 \\
\hline $\begin{array}{l}\text { C: } 1500 \text { UTC } 1 \text { Oct- } \\
0300 \text { UTC } 2 \text { Oct }\end{array}$ & 0.96 & -2.6 & 0.79 & 349 & 083 & 094 \\
\hline $\begin{array}{l}\text { D: } 0300 \text { UTC } 5 \text { Oct- } \\
1500 \text { UTC } 6 \text { Oct }\end{array}$ & 0.77 & -1.1 & 0.19 & 252 & 221 & 031 \\
\hline \multicolumn{7}{|l|}{ Event } \\
\hline $\begin{array}{l}\text { I: } 1500-2100 \text { UTC } \\
29 \text { Sep }\end{array}$ & 12.0 & 0.64 & -1.0 & 288 & 060 & 132 \\
\hline $\begin{array}{l}\text { II: } 0900-1500 \text { UTC } \\
2 \text { Oct }\end{array}$ & -3.6 & -0.12 & -1.0 & 265 & 180 & 085 \\
\hline $\begin{array}{l}\text { III: } 2100 \text { UTC } 2 \text { Oct- } \\
0900 \text { UTC } 3 \text { Oct }\end{array}$ & 7.4 & 1.36 & 1.0 & 313 & 228 & 085 \\
\hline $\begin{array}{l}\text { IV: } 1500 \text { UTC } 3 \text { Oct- } \\
2100 \text { UTC } 4 \text { Oct }\end{array}$ & -8.9 & 4.27 & -0.4 & 268 & 217 & 051 \\
\hline
\end{tabular}

More case studies are needed to decide how broad this moderate VWS-C range should be. Thus, high VWS-C is tentatively be defined as above $10 \mathrm{~m} \mathrm{~s}^{-1}$, and low VWS$\mathrm{C}$ is defined as below $6 \mathrm{~m} \mathrm{~s}^{-1}$.

The 6-h average values of various parameters for each segment are summarized in Table 1 . Segment A from 0900 UTC 28 September to 0900 UTC 29 September (Table 1) precedes the time before the first RI (Event I), which according to the SATCON peaked between 1500 and 2100 UTC 29 September. During segment B from 0300 UTC 30 September to 0900 UTC 1 October after the first RI, the intensity changes were steadily between 6 and $10 \mathrm{kt}(6 \mathrm{~h})^{-1}$, which over $24 \mathrm{~h}$ would satisfy the traditional RI definition of $30 \mathrm{kt} \mathrm{day}^{-1}$. As will be described below, this continued RI will be related to the rotation of the VWS-C direction to become east of north, and to the Ryglicki et al. (2018a) conceptual model of the structure of a TC that is in the midst of a RI in moderate VWS. Segment $\mathrm{C}$ is a period of the storm (1500 UTC 1 October-0300 UTC 2 October) when the direction of VWS-C has rotated back to being west of north but is also of much interest because it is when the track reversal occurs (Fig. 1 and Fig. 5b). Event II is that counterintuitive event mentioned above that is characterized by decreasing intensity in low VWS-C that occurs between 0900 and 1500 UTC 2 October (Table 1). Another environmental factor of ocean cooling during the looping track of Joaquin will be proposed to explain this intensity decrease. Event III from 2100 UTC 2 October to 0900 UTC 3 October includes the second RI event that appears in Fig. 5a to be almost concurrent with a rapid increase in VWS-C (Fig. 5c). Event IV from 1500 UTC 3 October to 2100 UTC 4 October includes the extremely rapid decay, and the subsequent segment D from 0300 UTC 5 October to 1500 UTC 6 October after the interrupted rapid decay has been discussed by Elsberry et al. (2018) and Hendricks et al. (2018).

\section{a. Segment $A$ and Event I: Pre-RI and first RI}

Berg (2016) states that it was the north-northwest shear (based on VWS-S) that prevented Joaquin from strengthening during segment $\mathrm{A}$, but then Joaquin moved over very warm water $\left(30^{\circ} \mathrm{C}\right)$, and $\mathrm{NHC}$ declared Joaquin to be a tropical storm at 1200 UTC 29 September. The VWS-C magnitude as a deviation from a moderate value was $+2.0 \mathrm{~m} \mathrm{~s}^{-1}$ during segment A and had a direction of $304^{\circ}$ (from the west-northwest) (Table 1, row 1). Thus, this strong VWS was impinging almost perpendicularly on the pre-Joaquin circulation that had a storm direction of $43^{\circ}$ (from the northeast). Thus, it is not surprising that the average 6-h intensity change is only $1.6 \mathrm{kt}$ during segment $\mathrm{A}$ according to the SATCON estimates. Although the correlation coefficient is small (0.12), it is noteworthy that the sign is positive (i.e., pre-Joaquin is slightly intensifying under larger than moderate VWS-C). 

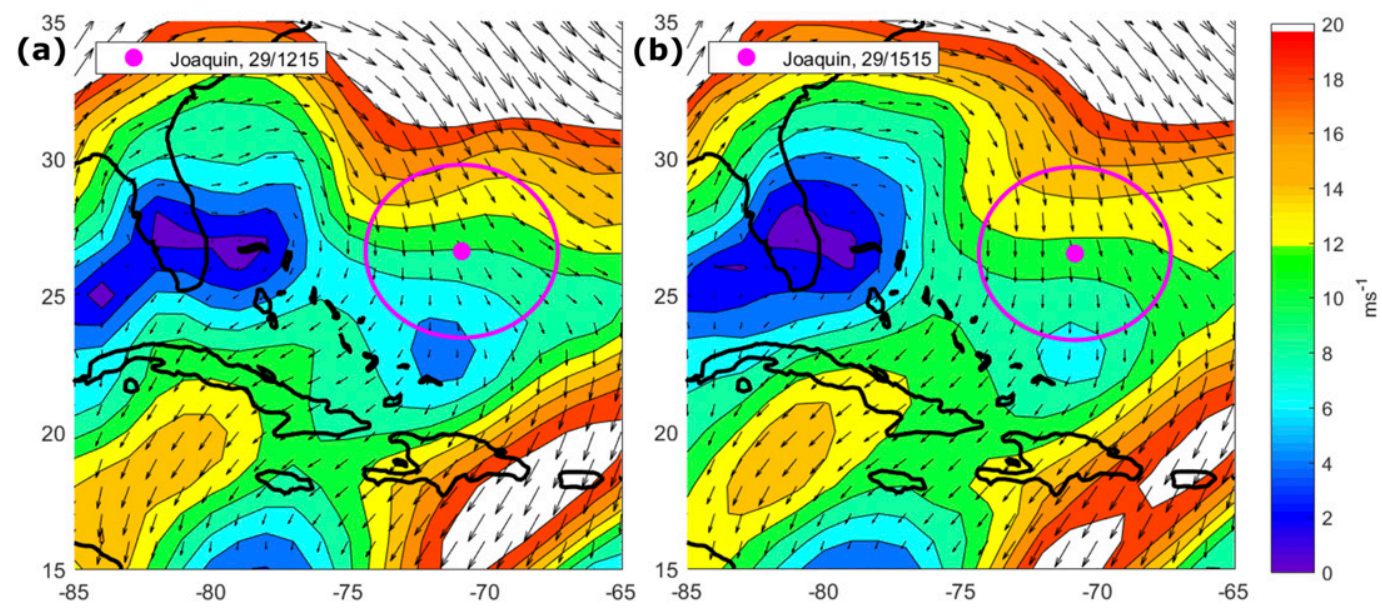

FIG. 6. Horizontal plots of the VWS-C vectors $\left(\mathrm{m} \mathrm{s}^{-1}\right.$; color scale on right side) relative to the SATCON position of Joaquin (magenta dot) at (a) 1215 and (b) 1515 UTC 29 Sep 2015 during the first RI. The averaging circle with a radius of $350 \mathrm{~km}$ for the VWS-C directions and magnitudes in Fig. 5 and Table 1 is also indicated.

As discussed earlier, the first RI of Joaquin peaks at 2100 UTC 29 September according to the SATCON estimates (Fig. 5a), but not until 2100 UTC 30 September for the NHC best track (Fig. 2). This SATCON peak intensity change at 2100 UTC 29 September correlates in time with a decrease in VWS-C (Fig. 5c). While the VWS$\mathrm{C}$ did decrease, it only decreased into the moderate range to a minimum of $8.6 \mathrm{~m} \mathrm{~s}^{-1}$ averaged over Event I (Table 1, row 5). Even with this small VWS-C decrease over a short period, the average intensity change of $12 \mathrm{kt}(6 \mathrm{~h})^{-1}$ led to a correlation coefficient of -1.0 , which is the expected negative correlation with a decrease in VWS-C leading to an intensification. In this case, it was only a small decrease into the moderate VWS-C range that was associated with the first RI.

Note also that this first RI event occurs when the VWS-C direction is $132^{\circ}$ off of the southwestward storm direction (Table 1, row 5). However, between 1215 UTC (Fig. 6a) and 1515 UTC (Fig. 6b) 29 September the VWS-C direction shifts to a more northerly direction. Although Berg (2016) attributes this VWS-C shift to the ridge off the southeast coast of the United States building farther into the Atlantic, the short-wave trough moving past to the north of Joaquin is considered to have the larger influence on the VWS-C direction change. This is an example of a situation in which further analysis of other environmental influences is required to diagnose the relative contributions to the RI event. Of note, it is also likely that Joaquin's southwestward translation over warmer waters contributed to the first $\mathrm{RI}$ as well.

A GOES-East infrared satellite image at 1815 UTC 29 September about $3 \mathrm{~h}$ prior to the SATCON first peak RI reveals a well-defined central dense overcast
(CDO) with strong outflow in a semicircle from the north-northeast anticyclonically around to the southsouthwest (Fig. 7). By contrast, the outflow is constrained in the entire northwest quadrant of the CDO, which is consistent with VWS-C vectors to the northwest of the Joaquin center in Fig. 6. Whereas those vectors appear to indicate that the northwesterly VWS$\mathrm{C}$ vectors have penetrated to the center, satellite imagery (Fig. 7) suggests that the strong outflow in the northwest quadrant has "fought-off" the impinging VWS-C (recall that the upper layer in the calculation is between 150 and $300 \mathrm{mb}$ ). Elsberry and Jeffries (1996) had noted such an interaction in which the outflow of Typhoon Robin (1993) had modulated the development of Tropical Storm Steve (1993). Elsberry and Park (2017) have suggested that such an outflow-VWS interaction was a contributing factor in the timing of the RI of Hurricane Earl (2010). Based on the abrupt SATCON intensity increase at 1800 UTC 29 September in Fig. 3 (red line), the proposed explanation is that a deep convection burst occurred during the first RI event of Joaquin such that the outflow in the northwest quadrant was able to prevent the VWS-C associated with the flow from the northwest from penetrating to the center.

\section{b. Segment B: Postpeak RI}

The postpeak RI segment B is an interesting period as Joaquin continued to intensify at an average rate of $7.5 \mathrm{kt}(6 \mathrm{~h})^{-1}$ (Table 1 , row 2), which then meets the $30 \mathrm{kt}(24 \mathrm{~h})^{-1}$ criterion for an extended $(30 \mathrm{~h})$ RI. Again, this continued RI occurred in a moderate VWS$\mathrm{C}$ of $8.11 \mathrm{~m} \mathrm{~s}^{-1}$, and the correlation with the SATCON intensity changes is negative (Table 1 , column 4 ). While 


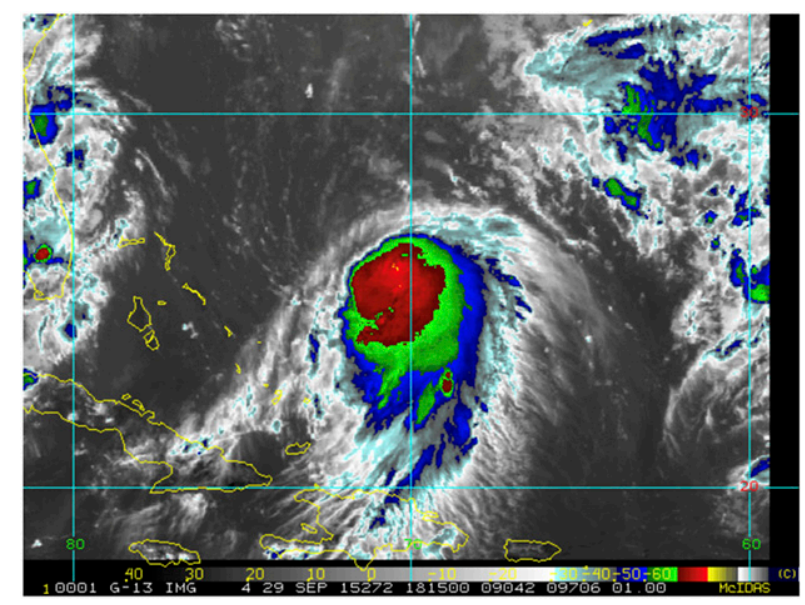

FIG. 7. Enhanced infrared image $(\sim 11 \mu \mathrm{m})$ at 4 -km resolution from GOES-East at 1815 UTC 29 Sep 2015 during the Event I peak RI of Hurricane Joaquin (https://rammb-data.cira.colostate.edu/ tc_realtime/).

Joaquin was still moving southwestward (direction $39^{\circ}$ ), the VWS-C had a direction of $6^{\circ}$ (just east of the north) (Table 1, column 5). Since the area-average VWS-C vector had become more aligned with the storm direction, one contribution to the continued RI is considered to have been associated with the tilt of the vortex due to the following VWS-C (i.e., the warm core aloft is being advected in the same direction as the low-level pressure center of Joaquin). Unfortunately, the first NASA WB57 mission with the HDSS dropwindsondes deployed from $60000 \mathrm{ft}$ that Creasey and Elsberry (2017) used to diagnose the vortex tilts in Joaquin was not until $36 \mathrm{~h}$ after the end of segment $B$.

Ryglicki et al. (2018a, their Fig. 1) propose a conceptual model of the tilted vortex structure of a TC that is in the midst of a RI in moderate VWS similar to the VWS-C that existed during segment B (Table 1, row 3 ). Ryglicki et al. (2018a,b) define a convective cloud structure that they call "tilt-modulated convective asymmetry" (TCA) that pulses over the core of the TC with a periodicity between 4 and $8 \mathrm{~h}$. Ryglicki et al. (2019, their Fig. 2) then present a schematic of how a strong TC outflow during a RI event can deflect the upper-tropospheric flow. In the Ryglicki et al. (2019) idealized model of a RI in moderate VWS, the simulated upper-tropospheric flow does not penetrate to the center due to the TCA pulses of outflow, which is analogous to the VWS-C vectors not penetrating the center in Fig. 6a. A future modeling study is planned to evaluate whether the long-lasting (30h) RI during segment B in Joaquin can be explained by say five such TCA pulses of outflow deflecting the VWS-C as in Ryglicki et al. (2019). An alternate explanation from
Chen et al. (2018) is a convective precipitation shield (CPS) embedded in the downshear convergence zone that induces a mesoscale positive vorticity band in which mesovortices form and rotate cyclonically around the TC center. In the Chen et al. (2018) simulation, a sufficient number of these mesovortices will facilitate the upscale growth of one mesovortex that becomes an inner vortex that will rapidly intensify.

Area-averaged and time-averaged VWS-C over the period of segment B in Table 1 (row 2) obscure some complex spatial and temporal variations in the VWS-C fields (Fig. 8). While the VWS-C vectors at 0915 UTC 30 September (Fig. 8a) are in the moderate range and are relatively uniform over the $350-\mathrm{km}$ radius, the midlatitude shortwave trough to the north of Joaquin in Fig. 6 has translated to the east so that the VWS-C vectors in the northeast quadrant of Joaquin are more aligned with the outflow in that quadrant. Furthermore, the connection of the VWS-C vectors associated with the outflow toward the southeast with the area with large VWS-C vectors to the southeast would be favorable for continued RI. Just $6 \mathrm{~h}$ later (Fig. 8b), an area of smaller VWS-C between Joaquin and the upper-level trough over the southeastern United States is beginning to move into the $350-\mathrm{km}$ radius circle to the north of Joaquin. Nevertheless, the area-average VWS-C remains in the moderate range due to the larger VWS-C values to the east and southeast of Joaquin. By 0315 UTC 1 October (Fig. 8c), Joaquin is located between a region of near-zero VWS$\mathrm{C}$ to the northwest and a region of very large VWS-C to the southeast. So even though the area-average VWS-C is still in the lower-moderate range (Fig. 5c), the intensity change per $6 \mathrm{~h}$ is clearly in the RI category (Fig. 5a). At the end of segment $B$ when the center of Joaquin was over the Bahamas (Fig. 8d), almost the entire 350-kmradius circle encompassed smaller than moderate VWS$\mathrm{C}$ vectors. This complex environmental interaction with Joaquin during the segment B continued RI has been able to be described only because high temporal and spatial resolution AMVs have been incorporated into the CIMSS VWS technique.

\section{c. Segment $C$ and Event II: Track reversal and pre-RI}

Even though the VWS-C during segment $\mathrm{C}$ may be categorized as low at an average value of $-2.6 \mathrm{~m} \mathrm{~s}^{-1}$ below moderate VWS of $8 \mathrm{~m} \mathrm{~s}^{-1}$ (Table 1, row 3), Joaquin had an average intensity change of only $0.96 \mathrm{kt}$ $(6 \mathrm{~h})^{-1}$ for this short segment. Furthermore, the correlation between the SATCON intensity changes and the VWS-C during segment $C$ is positive ( 0.79 , but again the magnitude is not as important as the sign). According to Berg (2016), this was the time that Joaquin made 

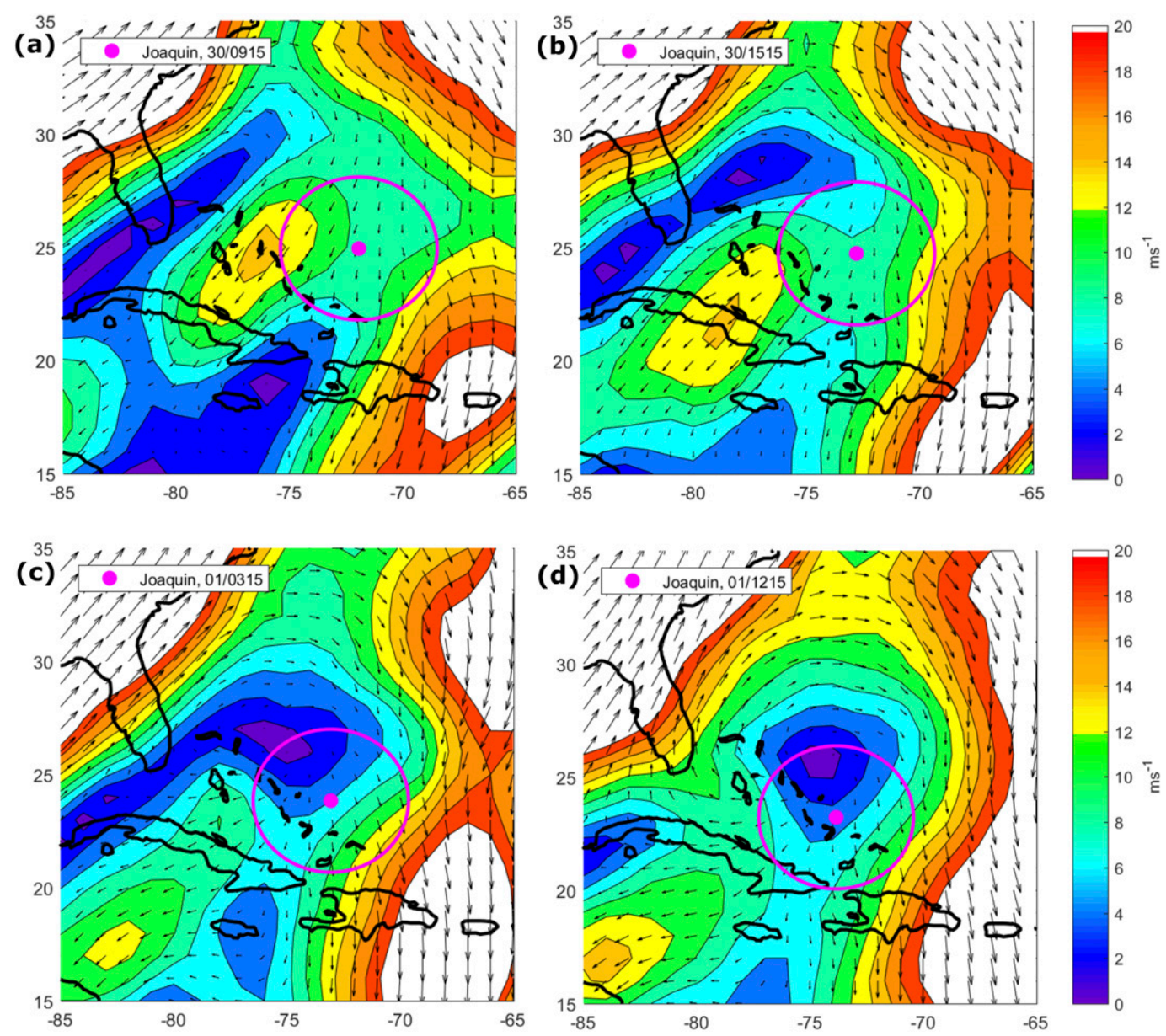

FIG. 8. Horizontal plots of the VWS-C vectors relative to the SATCON storm center position as in Fig. 6, but during the segment B continued RI at (a) 0915 UTC $30 \mathrm{Sep}$, (b) 1515 UTC $30 \mathrm{Sep}$, (c) 0315 UTC 1 Oct, and (d) 1215 UTC 1 Oct 2015.

landfall over the Bahamas. Although the interaction with small islands may have contributed to the weakening, it seems more likely that enhanced mixing at the base of the ocean mixed layer and/or upwelling in shallow water would have led to some ocean cooling (see section $3 \mathrm{~d}$ below).

Horizontal plots of the VWS-C vectors at 0615 UTC 2 October (Fig. 9a) do indicate that during segment $\mathrm{C}$ Joaquin was well within a region of small $\left(5 \mathrm{~m} \mathrm{~s}^{-1}\right)$ VWS-C averaged over the $350-\mathrm{km}$-radius circle, which is attributed to Joaquin being in a null region between large VWS-C associated with the upper-tropospheric troughs to the east and to the west. At the midpoint of Event II $6 \mathrm{~h}$ later at 1215 UTC 2 October, the track reversal of Joaquin has progressed (Fig. 5b, heading of $\sim 180^{\circ}$ from the south) and this movement has brought Joaquin into a region of larger VWS-C (Fig. 9b). As is also indicated in Fig. 5c, this increase in VWS-C is just into the range of moderate VWS $\left(\sim 8 \mathrm{~m} \mathrm{~s}^{-1}\right)$. Even though the VWS-C magnitude has increased to just $0.12 \mathrm{~m} \mathrm{~s}^{-1}$ below the moderate $8 \mathrm{~m} \mathrm{~s}^{-1}$ VWS, the average intensity change per $6 \mathrm{~h}$ is $-3.6 \mathrm{kt}$ during Event II (Table 1, row 6).

Whereas the correlation between the SATCON intensity changes per $6 \mathrm{~h}$ and the VWS-C was positive during segment $\mathrm{C}$, the correlation is negative during Event II. It seems counterintuitive that a hurricane with an intensity of 120 (NHC) or $112 \mathrm{kt}$ (SATCON) at 1200 UTC 2 October would have a decrease in intensity with just a small increase in VWS-C back into the middle of the moderate range.

\section{d. Ocean cooling as an environmental factor in Joaquin's intensity change during Event II}

An alternative to environmental VWS-C being responsible for the decreasing intensities during Event II is the ocean feedback to the Joaquin wind forcing. After the track reversal Joaquin had slowly moved poleward 

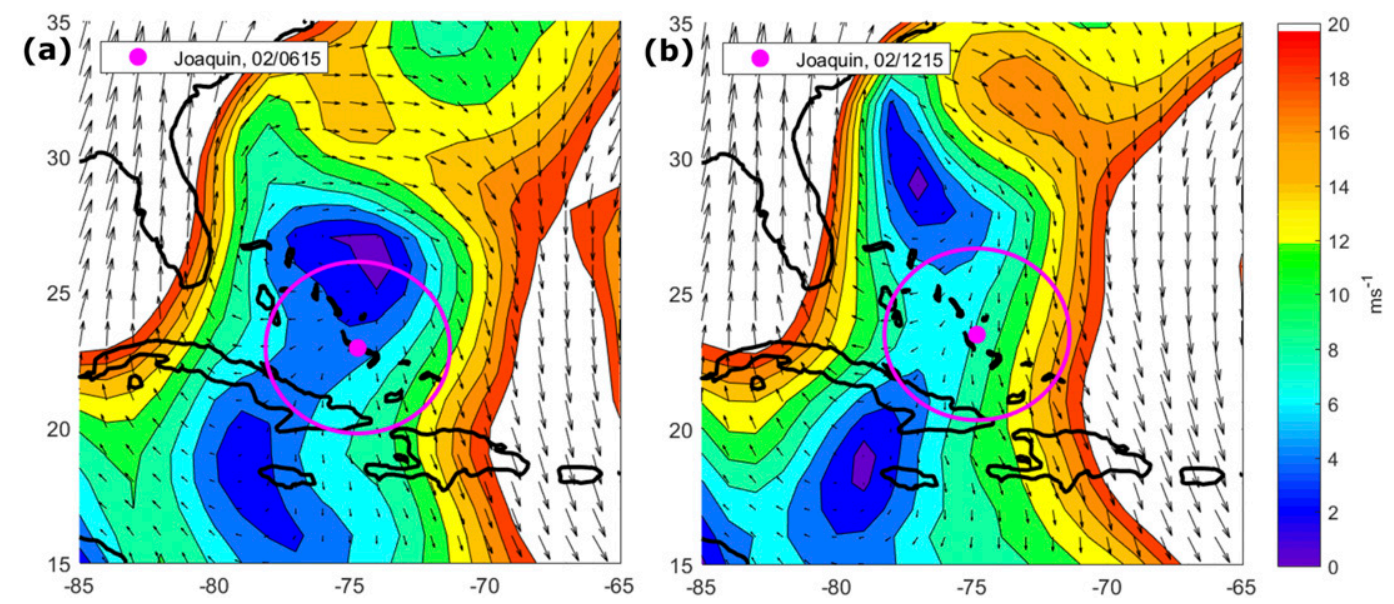

FIG. 9. Horizontal plots of the VWS-C vectors relative to the SATCON storm center position as in Fig. 6, but during the Joaquin track reversal at (a) 0615 and (b) 1215 UTC 2 Oct.

for $12 \mathrm{~h}$ and then had moved more rapidly toward the north-northeast (Fig. 1). This alternate explanation is proposed in a conceptual model of ocean cooling effects during the looping track reversal of Joaquin (Fig. 10). At storm translation speeds above $\sim 3 \mathrm{~m} \mathrm{~s}^{-1}$ the ocean cooling is mostly due to mixing processes (Shay 2010), and the combination of the vortex wind structure plus (or minus) the translation speed leads to stronger (or weaker) mixing processes on the right (or left) of the path in the Northern Hemisphere. Since the track reversal of Joaquin was an anticyclone loop (Fig. 1), if the ocean cooling was primarily due to mixing processes then the ocean region within the loop would have experienced larger cooling both during the southwestward track segment and the northeastward segment (Fig. 10a, dashed lines within the track).

No in situ ocean buoys or real-time sea surface temperature analyses have been located that would validate the development and magnitude of the ocean cooling inside the track loop in Fig. 10a. The NOAA Satellites and Information, Regional and Mesoscale Meteorology Branch (RAMMB) ocean heat content (OHC) analysis (RAMMB 2019) at 0000 UTC 1 October (Fig. 11a) does have an area of relative minimum $(35<\mathrm{OHC}<$ $50 \mathrm{~kJ} \mathrm{~cm}^{-2}$ ) with a similar shape as in Fig. 10a, but this feature does not extend southwestward to the initial position in the NHC track forecast (gray hurricane symbols) from 0000 UTC 1 October. Whereas the early portion of that NHC forecast represented rather well the Joaquin track at the bottom of the loop, the forecast after $36 \mathrm{~h}$ was northward to a landfall on the North Carolina coast rather than northeastward along the western edge of the ocean-cooled region as in Fig. 10a. The NHC track forecast from 0000 UTC 2 October was back to the northeast (not shown), but the RAMMB $\mathrm{OHC}$ analysis no longer had a region of minimum $\mathrm{OHC}$
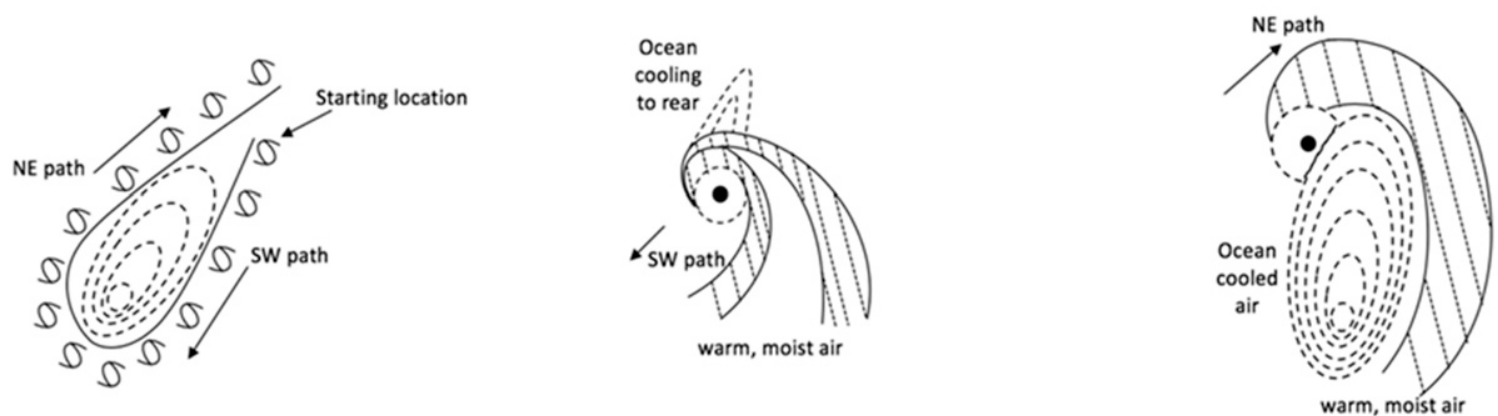

FIG. 10. Conceptual model of the ocean mixing effects during the looping track of Joaquin with (a) maximum ocean cooling (dashed lines) to right of track for both southwest (SW) path and northeast (NE) path. (b) During the SW path, the eyewall convection and rainbands wrap around the center with maximum ocean cooling trailing and to the right of the path. (c) During the NE path, a notch in the deep convection will exist over the ocean-cooled water because the warm, moist air that feeds the deep convection is to the east of the ocean-cooled region. 


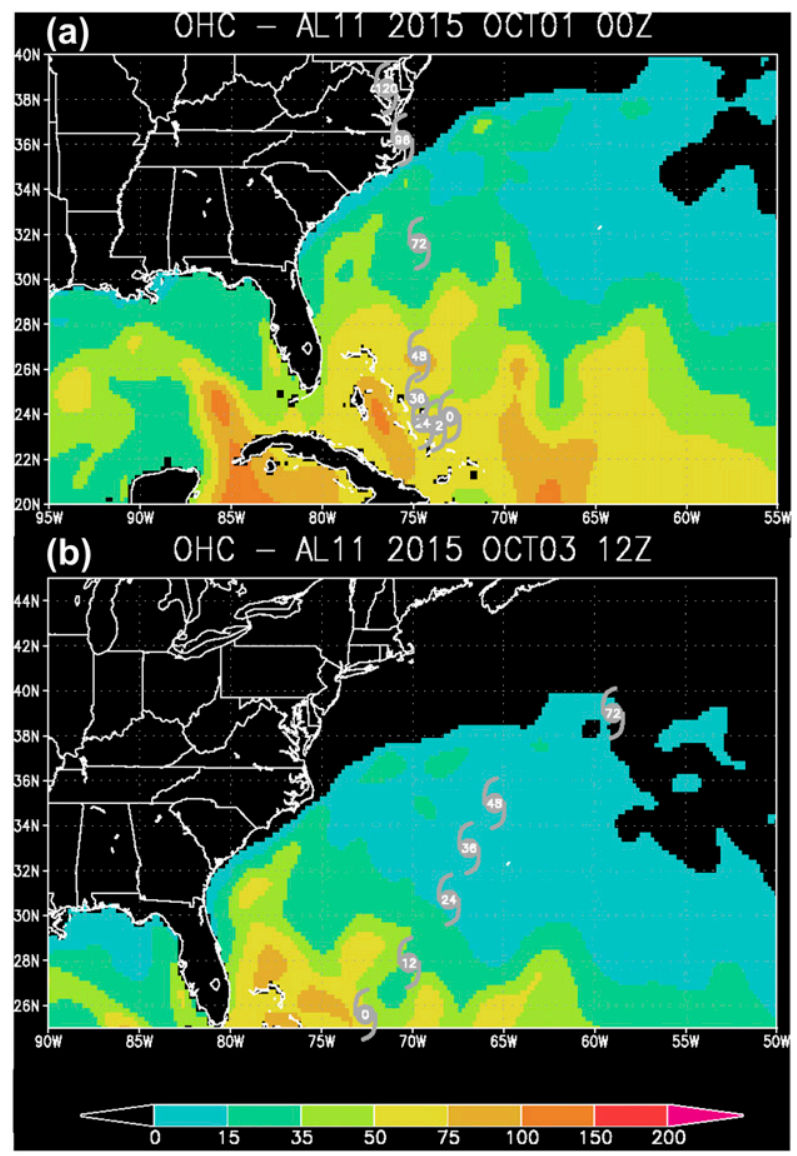

FIG. 11. Ocean heat content $\left(\mathrm{OHC} ; \mathrm{kJ} \mathrm{cm}^{-2}\right)$ analyses at (a) 0000 UTC 1 Oct and (b) 1200 UTC 3 Oct 2015 from the Regional and Mesoscale Meteorology Branch (RAMMB 2019). Gray hurricane symbols indicate the NHC forecast tracks from the initial time $(0 \mathrm{~h})$ and then at 12-h intervals and are not the best track positions (see text). Note the region of low OHC near the 0 and 12-h hurricane symbols has a similar shape as in the conceptual model in Fig. 10a.

within the track loop (Buholzer 2019; Fig. 15). However, a later RAMMB analysis at 1200 UTC 3 October (Fig. 11b) has a large region of lower $\mathrm{OHC}$ values with a similar shape as in Fig. 10a. Although considerable caution is advised regarding the magnitude and position of the low OHC region in Fig. 11b), this RAMMB analysis is highly suggestive of a region of ocean cooling inside the looping track of Joaquin.

Miller and Zhang (2019, their Fig. 3) provide parameterized wind-induced sea surface temperature (SST) decreases associated with the looping track of Joaquin calculated with a simple ocean mixed layer model developed for the Advanced Research version of the Weather Research and Forecast Model (ARW) by Davis et al. (2008), and assuming a spatially uniform initial ocean mixed layer depth of $30 \mathrm{~m}$ and a deep-layer lapse rate of $0.14 \mathrm{~K} \mathrm{~m}^{-1}$. The wind forcing is from their quadruple-nested (27-, 9-, 3-, and 1-km) control forecast initiated at 0600 UTC 29 September. The shape of the predicted SST decreases from the initial time until 1800 UTC 2 October is quite similar to the dashed lines in Fig. 10a, and the maximum SST decrease exceeds $3^{\circ} \mathrm{C}$. Miller and Zhang (their Fig. 4c) indicate that the SSTs averaged over a circle of $120-\mathrm{km}$ radius moved along the predicted path of Joaquin first increased to $29.8^{\circ} \mathrm{C}$ at 1200 UTC 30 September, but then decreased to $28.8^{\circ} \mathrm{C}$ at 2100 UTC when the path of Joaquin was northward away from the region with maximum SST decreases. The model-predicted maximum wind speed (Vmax) decreased from $63 \mathrm{~m} \mathrm{~s}^{-1}$ at 1200 UTC 1 October to $55 \mathrm{~m} \mathrm{~s}^{-1}$ at 1000 UTC 2 October when the westward path of Joaquin was parallel to the region of maximum SST decreases.

Given the hypothesized ocean-cooled region as in Fig. 10a, the low-level inflow into Joaquin during the southwestward path (Fig. 10b) would be bringing warmer and more moist air into the eastern semicircle versus cooler and drier air into the western semicircle. A contrast in surface enthalpy (sensible heat and latent heat) fluxes between the eastern and western semicircles would exist due to the maximum ocean cooling to the right side of the path. Some impacts of these decreased enthalpy fluxes over the ocean-cooled region on the deep convection relative to the center of Joaquin can be inferred from the 19-h sequence of enhanced infrared satellite imagery in Fig. 12. At 1715 UTC 1 October (Fig. 12a) when Joaquin was near the end of its southwestward path (Fig. 1, beginning of segment $\mathrm{C}$ ), no deep convection [yellow color, brightness temperature $(\mathrm{TB})<193 \mathrm{~K}$ ] is evident to the north and northeast of the center, which is the region of maximum ocean cooling expected for the prior southwestward path of Joaquin. The narrow band of deep convection in the western semicircle would be to the west of the ocean-cooled region in the conceptual model (Fig. 10b).

At the bottom of the loop around 0000 UTC 2 October (Fig. 1), deep convection was present at 2345 UTC 1 October (Fig. 12b) in a broad radial region within the southern semicircle, but no deep convection was in the northern semicircle. This absence of deep convection may be attributed to the ocean-cooled region that is expected to be a maximum just to the northeast of the eye at the bottom of the loop (see Fig. 10a, and Fig. 3 in Miller and Zhang 2019). A broad cyclonically curved rainband is in the southeast quadrant (Fig. 12b, yellow band representing from $-80^{\circ}$ to $-90^{\circ} \mathrm{C}$ directly south of the eye), but it does not encircle the eye when Joaquin was at the bottom of the loop. Just $8.5 \mathrm{~h}$ later at 0807 UTC 2 October (Fig. 12c), the enhanced IR image was rather disrupted in the eye region and the broad curved rainband to the southeast of the eyewall had shrunk in size relative to the 

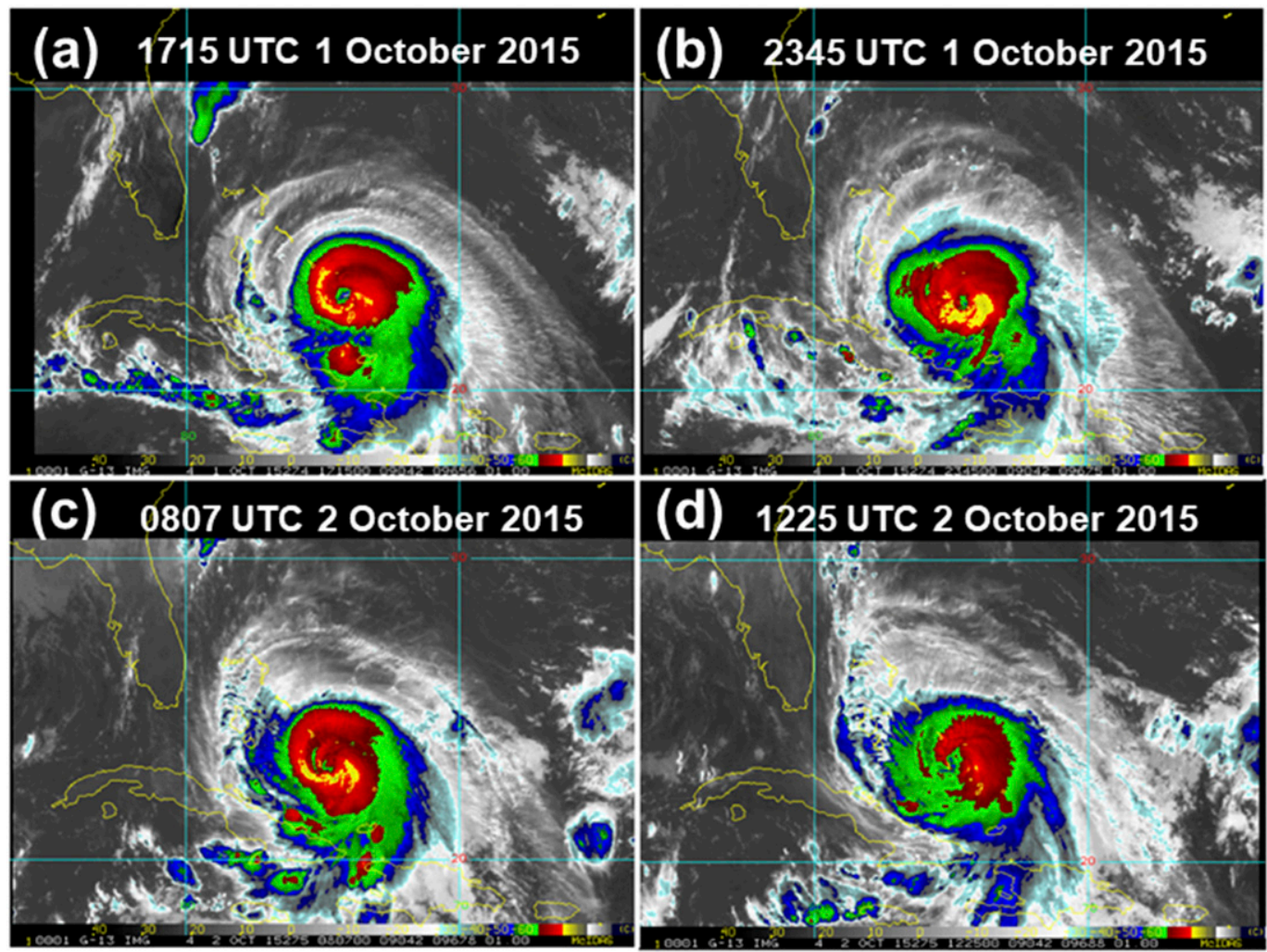

FIG. 12. Enhanced infrared imagery $(\sim 11 \mu \mathrm{m})$ at 4-km resolution from GOES-East as in Fig. 7, but during segment C and Event II at (a) 1715 UTC 1 Oct, (b) 2345 UTC 1 Oct, (c) 0807 UTC 2 Oct, and (d) 1225 UTC 2 Oct 2015. Note in (d) a notch in the deep convection analogous to the conceptual model in Fig. 10c.

Fig. 12b image. A narrow cyclonically curved rainband is now present in the southern semicircle, but it passes to the south of the eye to join the residual rainband to the southeast of the eye.

During the short northwestward path of Event II and the beginning of Event III (Fig. 1), most of the eastern semicircle of Joaquin is then hypothesized to have markedly reduced, and possibly even downward, enthalpy fluxes over the ocean-cooled region. Because the deep convection will necessarily be displaced to the east of the ocean-cooled region, the wrapping around of the narrow-curved rainband to the east of the ocean-cooled region in Fig. 12c is considered to be the start of the notch in the deep convection in the conceptual model in Fig. 10c. Only $4.5 \mathrm{~h}$ later at 1225 UTC 2 October (Fig. 12d), the notch in the deep convection was fully present over the ocean-cooled region in the region of green around $\sim 22^{\circ} \mathrm{N}, 75^{\circ} \mathrm{W}$ that is penetrating into the asymmetric convective area (red, representing from $-70^{\circ}$ to $-80^{\circ} \mathrm{C}$ ) around the eye and to the southeast.

Another hypothesized effect of the reduced enthalpy flux due to the ocean cooling on the right side of the short northwestward track of Joaquin during Event II (Fig. 1) would be some contribution to the SATCON intensity decrease $\left[-3.6 \mathrm{kt}(6 \mathrm{~h})^{-1}\right.$, Table 1$]$ when the VWS-C was in the moderate range. Even at 2100 UTC 2 October and 0300 UTC 3 October during the early stage of Event III when the VWS-C was still in the moderate range (Fig. $5 \mathrm{c}$ ), the relatively small SATCON intensity changes in the range of $1-4 \mathrm{kt}(6 \mathrm{~h})^{-1}$ (Fig. 5a) are likely in part associated with the reduced enthalpy fluxes over the ocean-cooled region. It is noteworthy that Hendricks et al. (2018, their Fig. 5a) have also documented that at 1800 UTC 2 October the vortex center could not be clearly defined from the dropwindsondes above $11.5 \mathrm{~km}$ (rather than extending higher in the upper troposphere), which is another indication of a weakening of Joaquin. In accordance with the conceptual model (Fig. 10c), it was only after Joaquin had moved to the northern end of the ocean-cooled region (Fig. 1) later in Event III that the second peak RI occurred at 0900 UTC 3 October. Therefore, the asymmetric deep convection in relation to the oceancooled region associated with the track loop is hypothesized to have contributed to the lack of intensification during Event II and delayed start of the second RI (Event III) despite relatively low VWS-C in the region of Joaquin (Fig. 5c). 


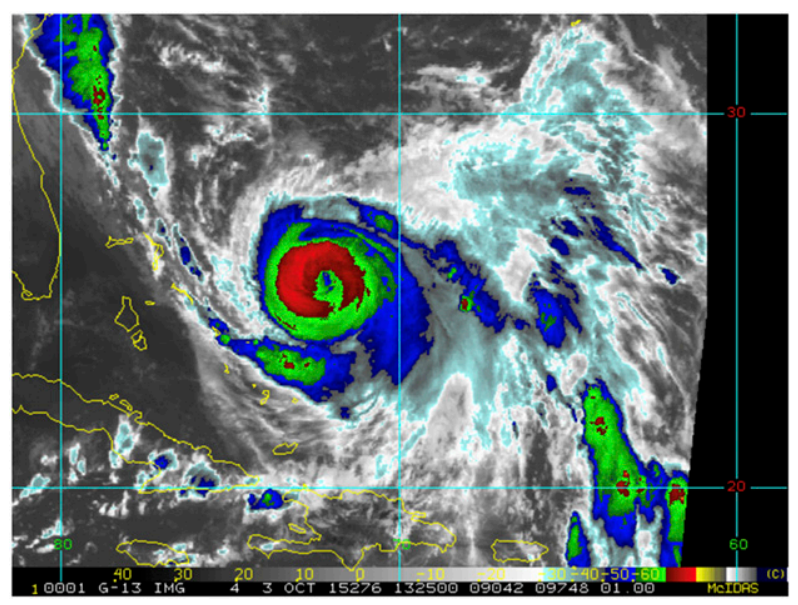

FIG. 13. Enhanced infrared imagery $(\sim 11 \mu \mathrm{m})$ at $4-\mathrm{km}$ resolution from GOES-East as in Fig. 7, but at 1325 UTC 3 Oct 2015, which is only $1 \mathrm{~h} 25 \mathrm{~min}$ after Joaquin attained peak intensity of $135 \mathrm{kt}$ at the end of the Event III second RI.

\section{e. Event III: Rapid intensification in high VWS}

The second RI event of Joaquin, which began at 2100 UTC 2 October and peaked at 0900 UTC 3 October (Fig. 5a) is the more interesting aspect of Event III. At 1800 UTC 2 October, the VWS-C of $7 \mathrm{~m} \mathrm{~s}^{-1}$ (Fig. 5c) is only slightly below moderate VWS with a small intensity change of $+2 \mathrm{kt}(6 \mathrm{~h})^{-1}$ (Fig. 5a). However, Joaquin's second RI event becomes readily apparent at 0000 UTC 3 October with a maximum intensity increase to $18 \mathrm{kt}(6 \mathrm{~h})^{-1}$. At $1325 \mathrm{UTC} 3$ October, which is $1.5 \mathrm{~h}$ after Joaquin attained peak intensity of $135 \mathrm{kt}$ (Berg 2016), and only $25 \mathrm{~h}$ after the satellite image in Fig. 12d, the deep convection in the eyewall has almost completely wrapped around the eye of Joaquin (Fig. 13).

The counterintuitive aspect of the second RI Event III is that it began during a period of moderate VWS-C, but the VWS-C then increased to a maximum value of $\sim 13 \mathrm{~m} \mathrm{~s}^{-1}$ (Fig. 5c) during the same 6-h interval as the SATCON intensity change has a value of $\sim 15 \mathrm{kt}$ $(6 \mathrm{~h})^{-1}$ (Fig. 5a). Since the VWS-C vectors in the tropics and subtropics are closely related to the uppertropospheric winds (including therefore outflow direction and magnitude), these higher wind speeds in the upper atmosphere will dominate the vector direction in the horizontal VWS plots. The moderate VWSC at 1945 UTC 2 October just prior to the beginning of the second RI was because Joaquin was between a preexisting southward-oriented VWS-C region to the east and a large northward-oriented VWS-C to the west that was associated with an approaching trough over the southeast United States (Fig. 14a). Although there is a hint of some outflow to the north in the cloud band originating near $\sim 26^{\circ} \mathrm{N}, 76^{\circ} \mathrm{W}$ (Fig. 13), the dominant outflow associated with Joaquin is toward the southeast on the eastern side of the center, and this is already reflected in the outward angle of the VWS-C vectors in Fig. 14a.

At 0915 UTC 3 October when the peak RI intensity change was occurring, the VWS-C vector field is highly asymmetric (Fig. 14b). While there is a region of VWS$\mathrm{C}$ values greater than $20 \mathrm{~m} \mathrm{~s}^{-1}$ to the east of the center that is clearly related to the outflow near $\sim 22^{\circ}$ to $28^{\circ} \mathrm{N}$, $68^{\circ} \mathrm{W}$ (Fig. 13), there is VWS-C across the center that is associated with a cyclonic vortex near $32^{\circ} \mathrm{N}, 67^{\circ} \mathrm{W}$ (Fig. 14b). Averaged over the circle of radius $350 \mathrm{~km}$, the VWS-C is $\sim 13 \mathrm{~m} \mathrm{~s}^{-1}$, which is then $5 \mathrm{~m} \mathrm{~s}^{-1}$ over the moderate value $\left(\sim 8 \mathrm{~m} \mathrm{~s}^{-1}\right)$. Based on these VWS-C vectors, it is asserted that the second RI of Joaquin could occur simultaneously with large VWS-C values due to a favorable interaction with that adjacent uppertroposphere trough to the northeast that contributed to an enhancement of the outflow from Joaquin as expected during a RI event.

The correlation of VWS-C magnitude deviations from a moderate $8 \mathrm{~m} \mathrm{~s}^{-1}$ value and the SATCON intensity changes during Event III is positive (Table 1, row 7), which suggests that the rapid intensity increase was at least coincident with, or perhaps actually leads, the VWS-C increase. After the track reversal $12 \mathrm{~h}$ prior to the start of the second RI event, the difference between the VWS-C $\left(313^{\circ}\right)$ direction and the storm direction $\left(228^{\circ}\right)$ is only $85^{\circ}$. Perhaps coincidentally, it was approximately $12 \mathrm{~h}$ before Joaquin's first RI event that the VWS heading and storm heading were also less than $90^{\circ}$ apart $\left(\sim 70^{\circ}\right)$ (Fig. 5b). Additional analyses and modeling studies are necessary to understand how this smaller difference between the VWS-C direction and the storm direction may have also contributed to Joaquin continuing to rapidly intensify despite the increasingly large magnitude of VWS-C.

\section{f. Event IV and segment D: Rapid decay and interrupted decay}

Elsberry et al. (2018) and Hendricks et al. (2018) have extensively examined the Event IV of Joaquin, which was characterized by extremely rapid decay and then an abrupt interruption in that decay, which is labeled as segment $\mathrm{D}$ in Fig. 5a. As described in section 2, the differences are that the VWS-C is here averaged over a $350-\mathrm{km}$-radius circle rather than a $500-\mathrm{km}$ circle, and 30-min SATCON intensity estimates are used rather than the 6-h NHC best track intensities (see Fig. 2). At the beginning of Event IV (1500 UTC 3 October), Joaquin was moving north-northeastward and was undergoing rapid decay in response to large $\left(17 \mathrm{~m} \mathrm{~s}^{-1}\right.$ ) VWS-C (Fig. 5c). Over the 12-h Event IV, 

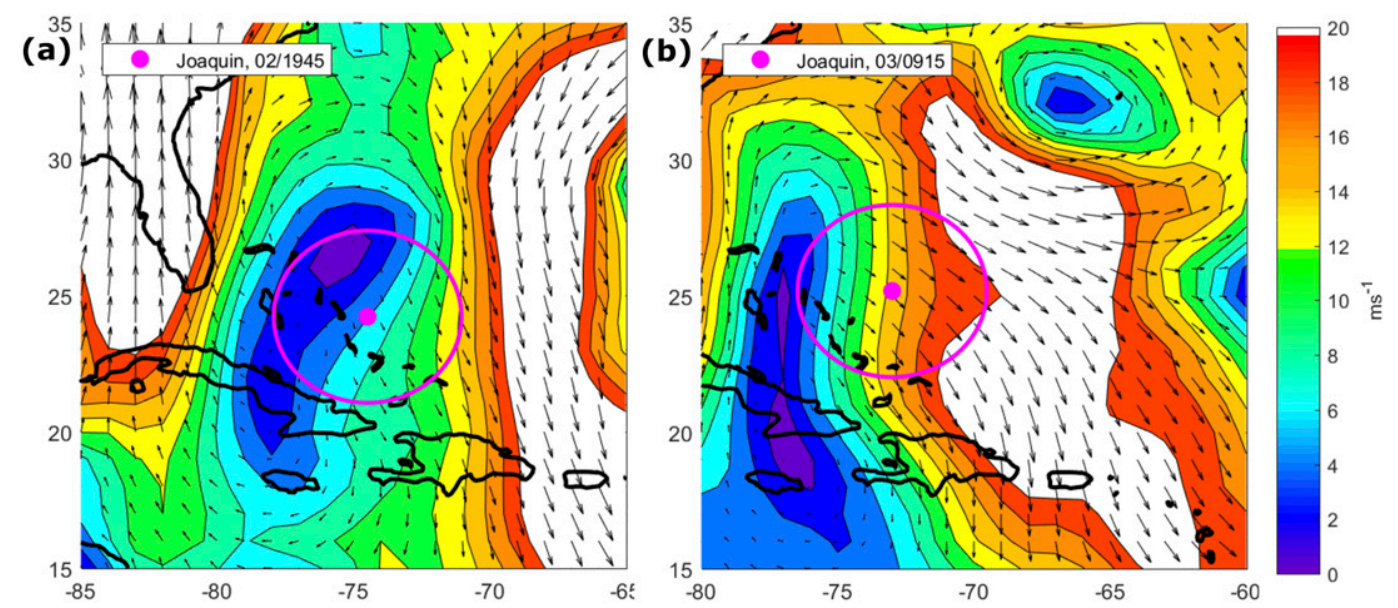

FIG. 14. Horizontal plots of the VWS-C vectors relative to the SATCON storm center position as in Fig. 6, but (a) at the beginning of Event III second RI at 1945 UTC 2 Oct and (b) just prior to the peak second RI at 0915 UTC 3 Oct when large VWS-C was over the center and to the northeast of Joaquin.

the average intensity change was $-8.9 \mathrm{kt}(6 \mathrm{~h})^{-1}$ in association with an average VWS-C of $12.27 \mathrm{~m} \mathrm{~s}^{-1}$ (Table 1, row 8), and thus the correlation coefficient was -0.4 .

At the interruption of the rapid decay on 0000 UTC 5 October according to the NHC best track, Joaquin was in the low-moderate VWS-C of $\sim 7 \mathrm{~m} \mathrm{~s}^{-1}$ (Fig. 5c). According to the SATCON intensity estimates, the decay continued another $6 \mathrm{~h}$ and then oscillated between weak intensification and weak decay (Fig. 5a). The VWS-C continued to decrease to $\sim 5 \mathrm{~m} \mathrm{~s}^{-1}$ at 0900 UTC 5 October, and then returned to the moderate VWS range $\left(\sim 8 \mathrm{~m} \mathrm{~s}^{-1}\right)$ around 1500 UTC 6 October. Averaged over segment $\mathrm{D}$, Joaquin had a slight positive intensity change $\left[0.77 \mathrm{kt}(6 \mathrm{~h})^{-1}\right]$ while in moderate VWS-C equal to $6.9 \mathrm{~m} \mathrm{~s}^{-1}$ (Table 1 , row 4 ). Thus, the correlation coefficient during segment $\mathrm{D}$ was positive (not negative as might be expected for a hurricane moving poleward over cold water), since the SATCON intensity change was increasing when the VWS-C was below the moderate definition, which is another example of nonlinear behavior during Joaquin. By contrast, the correlation coefficient between the NHC best track intensity changes and VWS-S would be 0.0 (Fig. 2), since the NHC intensities were constant at $75 \mathrm{kt}$ for $30 \mathrm{~h}$ during segment $\mathrm{D}$.

There were two times during segment $\mathrm{D}$ when Joaquin intensified immediately after the VWS-C directions and the storm directions were becoming closer (Fig. 5b). The first time was after 1800 UTC 4 October when the VWS-C direction and the storm direction were within $40^{\circ}$ (VWS-C from the west and storm direction from the southwest), and the second time was after 1500 UTC 6 October when the VWS-C and storm directions were almost the same (VWS-C from the west and storm direction from the west). At the first time, Joaquin's intensity increase was almost $15 \mathrm{kt}(6 \mathrm{~h})^{-1}$, and at the second time Joaquin's intensity increase was almost $10 \mathrm{kt}(6 \mathrm{~h})^{-1}$ (Fig. 5a).

As discussed for segments B and C, the VWS-C magnitudes were not uniform throughout the $350-\mathrm{km}$ radius circle at 1815 UTC 4 October near the end of the rapid decay (Fig. 15a) as well as at 1815 UTC 6 October (Fig. 15b) following the interrupted decay. Specifically, Joaquin was within a large north-south gradient in VWS-C throughout segment D. At 1815 UTC 4 October (Fig. 15a), there is an area to the north-northeast of the storm center with VWS-C $\sim 18 \mathrm{~m} \mathrm{~s}^{-1}$ and an area to the south-southeast with VWS-C $<4 \mathrm{~m} \mathrm{~s}^{-1}$. Since the outflow from Joaquin was also toward the north-northeast at this time, and the asymmetrical VWS-C in Fig. 15a was associated with an increase in the outflow, a slight intensification of Joaquin occurred rather than the expected decay in larger VWS-C. A similar VWS-C pattern existed later in segment D at 1815 UTC 6 October, except the VWS-C magnitude north-northeast of the storm was $>20 \mathrm{~m} \mathrm{~s}^{-1}$ in the direction of the outflow. Furthermore, the position of the short-wave trough to the west of the center is generally regarded as favorable to intensification (e.g., Hanley et al. 2001). Interestingly, the short-term reintensification on 6 October is larger than on 4 October (Fig. 5a), which suggests again the importance of the asymmetrical VWS-C pattern for intensity change prediction. In summary, there appears to be a connection between the storm direction and the VWS-C heading, as well as the positions of large VWS-C gradients relative to Joaquin that lead to short reintensification periods following the interrupted rapid 

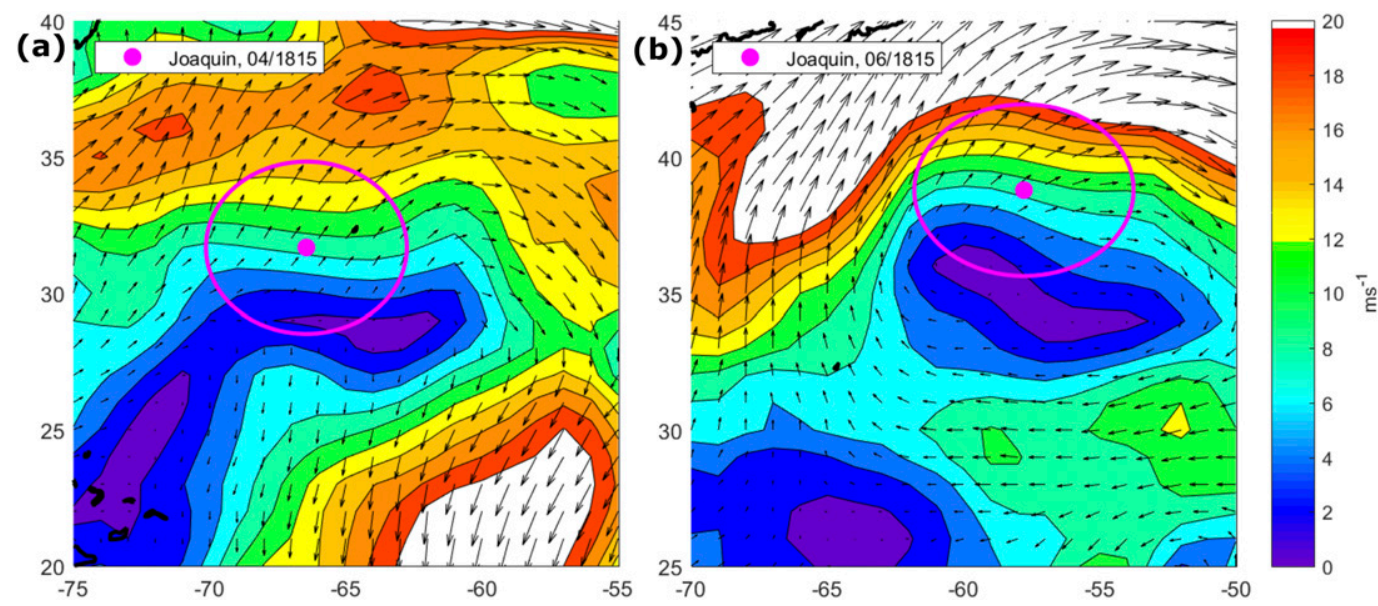

FIG. 15. Horizontal plots of the VWS-C vectors relative to the SATCON storm center position as in Fig. 6, but (a) near the end of the interruption of rapid decay at 1815 UTC 4 Oct and (b) two days later at 1815 UTC 6 Oct when Joaquin was still at hurricane strength moving poleward over cold water.

decay of Joaquin described in Elsberry et al. (2018) and Hendricks et al. (2018).

\section{Summary}

This study has used two special CIMSS datasets that are higher resolution (spatially and temporally) VWSs than the 6-h VWS-S, and the 30-min SATCON intensity estimates rather than the 6-h NHC best track intensities. Analysis of the SATCON dataset with observations every $30 \mathrm{~min}$ has documented intensity changes of Joaquin that cannot be resolved when only analyzing values at the 6-h synoptic times. Likewise, the VWS-C dataset demonstrated that there were multiple times during the Joaquin life cycle when the VWS-C magnitudes and directions rapidly changed between 6-h synoptic times. Since the new-generation geostationary satellites have the capability for imaging over the tropics at 10-min temporal resolution, this study demonstrates how products derived from this imagery could be developed to better analyze, understand, and predict the environmental VWS-C impacts on TC intensity change, including RI events.

Nonlinear relationships between environmental VWS$\mathrm{C}$ and Joaquin's intensification and decay have been demonstrated by correlating the SATCON intensity changes with the 15-min VWS-C dataset. In particular, the SATCON/VWS-C correlation coefficient was much higher than the correlation coefficient between the NHC best track intensities versus the 6-h SHIPS VWSs. Correlations between the VWS-C and the SATCON datasets were separately calculated for four intensity change events and adjacent periods of intensity change during Joaquin's life cycle, which further demonstrated the nonlinear relationships between the environmental VWS-C and the SATCON intensity changes.

The concept of a "moderate" VWS-C has been used in Fig. $5 \mathrm{c}$ and Table 1 to compare the VWS-C with the intensity changes of Joaquin, with a value of around $8 \mathrm{~m} \mathrm{~s}^{-1}$ being defined as "moderate." It was demonstrated that even small changes above and below the $8 \mathrm{~m} \mathrm{~s}^{-1}$ value were associated with both the intensification periods and the rapid decay of Joaquin. In segment A, a small VWS-C increment above $8 \mathrm{~m} \mathrm{~s}^{-1}$ was sufficient to delay intensification of a tropical depression to become Tropical Storm Joaquin. However, Joaquin underwent the first RI when only a small VWS-C decrease to near $8 \mathrm{~m} \mathrm{~s}^{-1}$ occurred. Once that first peak RI occurred, RI magnitude intensity changes continued for $30 \mathrm{~h}$ during segment B in association with VWS-C values of $\sim 8 \mathrm{~m} \mathrm{~s}^{-1}$.

In the counterintuitive Event II, the SATCON (and the NHC) intensity was decreasing even though VWS-C became as small as $\sim 4 \mathrm{~m} \mathrm{~s}^{-1}$. Indeed, such small VWS values would normally be expected to be associated with RI rather than decreasing intensities. A conceptual model has been proposed (Fig. 10) as to how the ocean cooling during the southwestward path of Joaquin may explain the intensity decreasing when the VWS-C was so small. Whereas two RAMMB OHC analyses do indicate a region of $\mathrm{OHC}$ decreases within the Joaquin track loop that is consistent with the conceptual model, the Miller and Zhang (2019) model-predicted region of SST decreases within the Joaquin looping track is better evidence of the ocean-cooling magnitudes and locations. Satellite imagery over a 19-h period suggests how a notch in the deep convection over the ocean-cooled air developed as the warm, moist inflow was displaced well to the east of the center. A fully coupled ocean-atmospheric model will be 
required to analyze and to predict the ocean cooling and its effects on the Joaquin intensity changes.

The second RI began when the VWS-C had only increased to moderate VWS values between 7 and $8 \mathrm{~m} \mathrm{~s}^{-1}$. Perhaps the most counterintuitive event during Joaquin was that the peak 6-h intensity change of $15 \mathrm{kt}$ during the second RI was essentially concurrent with a 6-h average VWS-C of $13 \mathrm{~m} \mathrm{~s}^{-1}$, which would normally be expected to be associated with a rapid intensity decrease. This counterintuitive event occurred as Joaquin was approaching an upper-tropospheric cyclone that contributed to an enhanced outflow while simultaneously increasing the highly asymmetric VWS-C within a 350-km-radius circle. Immediately after the second RI led to the peak intensity of Joaquin, extreme decay rates of 5-10 kt $(6 \mathrm{~h})^{-1}$ occurred during Event IV that ended shortly after 2100 UTC 4 October when the VWS-C had decreased only into the moderate range at $8 \mathrm{~m} \mathrm{~s}^{-1}$. According to the SATCON intensity estimates, the interrupted rapid decay after 0600 UTC 5 October was followed by small intensifications or decays when the VWS-C continued in the moderate range. In conclusion, this Joaquin case well illustrates that the relationship between environmental VWS and tropical cyclone intensity change is not linearrather this relationship can be highly nonlinear.

Acknowledgments. This study is part of the M. S. thesis of LT (USN) Buholzer (2019) in the Department of Meteorology at the Naval Postgraduate School under the direction of Emeritus Professor Russell Elsberry and Professor Wendell Nuss. Russell Elsberry is supported by Office of Naval Research Grant N000141712160, Chris Velden is supported by ONR Grant N000141613033, and Mary Jordan is supported by ONR Grant N0001417WX01042. Special thanks to Derrick Herndon and Dave Stettner at the Cooperative Institute for Meteorological Satellite Studies for providing the 15 -min vertical wind shear calculations and the 30-min SATCON intensities. Finally, this study could not have been done without the entire Office of Naval Research Tropical Cyclone Intensity (2015) field experiment mission support team. Penny Jones provided excellent support during the manuscript preparation.

\section{REFERENCES}

Berg, R. L., 2016: Hurricane Joaquin (28 September-7 October 2015). National Hurricane Center Tropical Cyclone Rep. AL112015, 36 pp., https://www.nhc.noaa.gov/data/tcr/AL112015_Joaquin.pdf.

Buholzer, N., 2019: Observations of environmental factors affecting intensity changes during the track reversal of Hurricane Joaquin (2015). M. S. thesis, Dept. of Meteorology, Naval Postgraduate School, $70 \mathrm{pp}$.

Chen, X., Y. Wang, J. Fang, and M. Xue, 2018: A numerical study of rapid intensification of Typhoon Vicente (2012) in the South
China Seas. Part II: Roles of inner-core processes. J. Atmos. Sci., 75, 235-255, https://doi.org/10.1175/JAS-D-17-0129.1.

Creasey, R. L., and R. L. Elsberry, 2017: Tropical cyclone center positions from sequences of HDSS sondes deployed along high-altitude overpasses. Wea. Forecasting, 32, 317-325, https://doi.org/10.1175/WAF-D-16-0096.1.

Davis, C. A., and Coauthors, 2008: Prediction of landfalling hurricanes with the Advanced Hurricane WRF Model. Mon. Wea. Rev., 136, 1990-2005, https://doi.org/10.1175/ 2007MWR2085.1.

DeMaria, M., M. Mainelli, L. K. Shay, J. A. Knaff, and J. Kaplan, 2005: Further improvements to the Statistical Hurricane Intensity Prediction Scheme (SHIPS). Wea. Forecasting, 20, 531-543, https://doi.org/10.1175/WAF862.1.

Doyle, J., and Coauthors, 2017: A view of tropical cyclones from above: The Tropical Cyclone Intensity experiment. Bull. Amer. Meteor. Soc., 98, 2113-2134, https://doi.org/10.1175/BAMS-D-16-0055.1.

Elsberry, R. L., and R. Jeffries, 1996: Vertical wind shear influences on tropical cyclone formation and intensification during TCM92 and TCM-93. Mon. Wea. Rev., 124, 1374-1387, https://doi.org/ 10.1175/1520-0493(1996)124<1374:VWSIOT>2.0.CO;2.

— and evolution of Hurricane Earl (2010) during rapid intensification." Mon. Wea. Rev., 145, 1565-1571, https://doi.org/ 10.1175/MWR-D-16-0301.1.

, E. Hendricks, C. Velden, M. Bell, M. Peng, E. Casas, and Q. Zhao, 2018: Demonstration with special TCI-15 datasets of potential impacts of new-generation satellite atmospheric motion vectors on Navy regional and global models. Wea. Forecasting, 33, 1617-1637, https://doi.org/10.1175/WAF-D-17-0168.1.

Gallina, G. M., and C. S. Velden, 2002: Environmental vertical wind shear and tropical cyclone intensity change utilizing enhanced satellite-derived wind formation. Preprints, 25th Conf. on Hurricanes and Tropical Meteorology, San Diego, CA, Amer. Meteor. Soc., 172-173.

Hanley, D., J. Molinari, and D. Keyser, 2001: A composite study of the interactions between tropical cyclones and upper-tropospheric troughs. Mon. Wea. Rev., 129, 2570-2584, https://doi.org/10.1175/ 1520-0493(2001)129<2570:ACSOTI>2.0.CO;2.

Hendricks, E. A., M. Peng, B. Fu, and T. Li, 2010: Quantifying environmental on tropical cyclone intensity change. Mon. Wea. Rev., 138, 3243-3271, https://doi.org/10.1175/2010MWR3185.1.

, R. L. Elsberry, C. S. Velden, A. Jorgensen, M. S. Jordan, and R. Creasey, 2018: Environmental factors and internal processes contributing to interrupted rapid decay of Hurricane Joaquin (2015). Wea. Forecasting, 33, 1251-1262, https:// doi.org/10.1175/WAF-D-17-0190.1.

Herndon, D., and C. S. Velden, 2018: An update on the CIMSS SATellite CONsensus (SATCON) tropical cyclone intensity algorithm. 33rd Conf. on Hurricanes and Tropical Meteorology, Ponte Vedra Beach, FL, Amer. Meteor. Soc., 284, https://ams.confex.com/ams/33HURRICANE/webprogram/ Paper340235.html.

Jorgensen, A., 2017: Factors contributing to the interrupted decay of Hurricane Joaquin (2015) in a moderate vertical wind shear environment. M.S. thesis, Dept. of Meteorology, Naval Postgraduate School, $97 \mathrm{pp}$.

Miller, W., and D.-L. Zhang, 2019: Understanding the unusual looping track of Hurricane Joaquin (2015) and its forecast errors. Mon. Wea. Rev., 147, 2231-2259, https://doi.org/10.1175/MWR-D-180331.1.

Olander, T., and C. S. Velden, 2019: The Advanced Dvorak Technique (ADT) for estimating tropical cyclone intensity: 
Update and new capabilities. Wea. Forecasting, 34, 905-922, https://doi.org/10.1175/WAF-D-19-0007.1.

RAMMB, 2019: Tropical Cyclone Archive: Hurricane Joaquin (2105). Accessed 21 February 2019, https://rammb-data.cira.colostate.edu/ tc_realtime/.

Rios-Berrios, R., and R. D. Torn, 2017: Climatological analysis of tropical cyclone intensity changes under moderate vertical wind shear. Mon. Wea. Rev., 145, 1717-1738, https://doi.org/ 10.1175/MWR-D-16-0350.1.

Ryglicki, D. R., J. H. Cossuth, D. Hodyss, and J. D. Doyle, 2018a: The unexplained rapid intensification of tropical cyclones in moderate vertical wind shear. Part I: Overview and observations. Mon. Wea. Rev., 146, 3773-3800, https://doi.org/10.1175/ MWR-D-18-0020.1.

— J. J. Doyle, Y. Jin, D. Hodyss, and J. H. Cossuth, 2018b: The unexplained rapid intensification of tropical cyclones in moderate vertical wind shear. Part II: Vortex tilt. Mon. Wea. Rev., 146, 3801-3825, https://doi.org/10.1175/MWR-D-18-0021.1.

,-- , D. Hodyss, Y. Jin, K. C. Viner, and J. M. Schmidt, 2019: The unexplained rapid intensification of tropical cyclones in moderate vertical wind shear. Part III: Outflow-environment interaction. Mon. Wea. Rev., 147, 2919-2940, https://doi.org/ 10.1175/MWR-D-18-0370.1.

Shay, L. K., 2010: Air-sea interactions in tropical cyclones. Global Perspectives of Tropical Cyclones, J. C. L. Chan et al., Eds., World Scientific, 93-131.

Stettner, D. C., C. S. Velden, R. Rabin, S. Wanzong, J. Daniels, and W. Bresky, 2019: Development of enhanced vortex-scale atmospheric motion vectors for hurricane applications. Remote Sens., 11, 1981, https://doi.org/10.3390/RS11171981.

Velden, C. S., and J. Sears, 2014: Computing deep-tropospheric vertical wind shear analyses for tropical cyclone application: Does the methodology matter? Wea. Forecasting, 29, 11691180, https://doi.org/10.1175/WAF-D-13-00147.1.

— , and D. Stettner, 2018: Improved monitoring of the evolving upper-tropospheric wind fields over the core of tropical cyclones aided by high spatiotemporal resolution GOES-16 atmospheric motion vectors. 33rd Conf. Hurricanes and Tropical Meteorology, Ponte Vedra Beach, FL, Amer. Meteor. Soc. 245, https://ams.confex.com/ams/33HURRICANE/webprogram/ Paper340240.html.

- , and Coauthors, 2005: Recent innovations in deriving tropospheric winds from meteorological satellites. Bull. Amer. Meteor. Soc., 86, 205-224, https://doi.org/10.1175/BAMS-862-205.

- - W. E. Lewis, W. Bresky, D. Stettner, J. Daniels, and S. Wanzong, 2017: Assimilation of high-resolution satellite-derived atmospheric motion vectors: Impact on HWRF forecasts of tropical cyclone track and intensity. Mon. Wea. Rev., 145, 1107-1125, https://doi.org/10.1175/MWR-D-160229.1.

Wang, Y., Y. Rao, Z.-M. Tan, and D. Schonemann, 2015: A statistical analysis of the effects of vertical wind shear on tropical cyclone intensity change over the western North Pacific. Mon. Wea. Rev., 143, 3434-3453, https://doi.org/10.1175/MWR-D15-0049.1. 